\title{
Design and Performance of Microlith Implemented Projectiles During the Middle and the Late Epipaleolithic of the Levant: Experimental and Archaeological Evidence
}

\section{Citation}

Yaroshevich Alla, Daniel Kaufman, Dnitri Nuzhnyy, Ofer Bar-Yosef, and Mina Weinstein-Evron. 2010. Design and performance of microlith implemented projectiles during the middle and the late Epipaleolithic of the Levant: Experimental and archaeological evidence. Journal of Archaeological Science 37(2): 368-388.

\section{Published Version}

doi:10.1016/j.jas.2009.09.050

\section{Permanent link}

http://nrs.harvard.edu/urn-3:HUL.InstRepos:4270545

\section{Terms of Use}

This article was downloaded from Harvard University's DASH repository, and is made available under the terms and conditions applicable to Open Access Policy Articles, as set forth at http:// nrs.harvard.edu/urn-3:HUL.InstRepos:dash.current.terms-of-use\#OAP

\section{Share Your Story}

The Harvard community has made this article openly available.

Please share how this access benefits you. Submit a story. 


\title{
Design and Performance of Microlith Implemented Projectiles During the Middle and the Late Epipaleolithic of the Levant: Experimental and Archaeological Evidence
}

\author{
Alla Yaroshevich ${ }^{1,2}$, Daniel Kaufman ${ }^{3}$, Dmitri Nuzhnyy ${ }^{4}$, \\ Ofer Bar-Yosef ${ }^{5}$, Mina Weinstein-Evron ${ }^{3}$ \\ ${ }^{1}$ University of Haifa, Department of Archaeology, Israel \\ ${ }^{2}$ Israel Antiquities Authority \\ ${ }^{3}$ Zinman Institute of Archaeology, University of Haifa, Israel \\ ${ }^{4}$ Institute of Archaeology, National Academy of Science, Kiev, Ukraine \\ ${ }^{5}$ Harvard University, Department of Anthropology, Peabody Museum of Archeology \\ and Ethnology, USA
}

\begin{abstract}
The study comprises an experimentally based investigation of interaction between temporal change in the morphology of microlithic tools and transformations in projectile technology during the Late Pleistocene in the Levant. Archery experiments with differently designed arrows fitted with various types of microliths representing subsequent Epipaleolithic cultures of the Levant allowed analyzing performance abilities of the arrows, identifying projectile damage types characteristic of particular hafting modes, detecting factors influencing the frequency of projectile damage and estimating the frequency of projectile damage expected to be found in archaeological samples. The data obtained through the experiments applied in the analysis of the archaeological microliths from Geometric Kebaran and Natufian sites in Israel indicate different approaches to the design of projectiles fitted with microliths characteristic for these cultures. The shift in design, associated with such important economic and social transformations as transition to sedentary settlements and a broad-spectrum economy, may reflect a demand for light, flexible and efficient projectile weapons requiring low time and labor investment for preparation and retooling. The use of such efficient weapons in conditions of growing population density and restricted areas available for Natufian huntergatherers can be considered as one of the factors that could have affected the subsequent transition to food production that took place in the early Holocene.

Key words: microliths, archery experiments, impact fractures, projectile weapons, Levant, Epipaleolithic
\end{abstract}

\section{Introduction}

Variability in artifacts attributed to projectile weapons has long been employed for dividing the prehistoric record into separate cultural and temporal units. This widely accepted practice indicates a connection between transformations in projectile technology and shifts in social and subsistence adaptations of prehistoric hunter-gatherers. Studies investigating major changes in prehistoric projectile technology show their close association with increased population density and 
decline in available resources resulting from environmental changes (Shea, 2006; $\mathrm{Yu}, 2006$ ). In the Levant, the end of the Pleistocene was a period of sharp environmental fluctuations and rapid cultural, social and subsistence changes that led subsequently to the emergence of agricultural communities in the early Holocene. Improvement in hunting skills and a resulting decrease in game have been suggested as one of the triggers that could possibly have started the process of transition from foraging to food production in the region (Diamond, 2002). The present study aims to test this hypothesis through an investigation of the functioning of projectile weapons used during the closing stages of the Pleistocene in the Levant.

The Late Pleistocene flint assemblages in the Levant do not yield any type of symmetrical points leaving microlithic tools as the only candidates to function as projectiles. Microliths dominate during the period and researchers use the temporal and spatial variability of these tools to divide the Late Pleistocene Epipaleolithic into separate cultures (Bar-Yosef, 1970, 1998; Goring-Morris, 1998; Henry, 1989). The Early Epipaleolithic Kebaran (ca. 20-16.5 ka cal BP) is characterized by a variety of non-geometric microliths: arch backed bladelets, Kebara points, microgravette points (Fig. 1a: 1, 2, 3). The Geometric Kebaran, the main middle Epipaleolithic culture (ca.16.5-14.5 ka cal BP) is characterized by the dominance of trapeze/rectangles elongated double truncated bladelets with straight backs (Fig. 1a: 4). The last Epipaleolithic culture, the Natufian (ca. 14.5-11.5 ka cal BP), is characterized by lunates -geometric microliths with curved back (Fig. 1a: 5, 6). Relatively large lunates with bifacial (Helwan) retouch dominate during the Early Natufian whereas during the Late Natufian small lunates modified by abrupt retouch are more common. The Final Natufian is defined by the almost exclusive production of very small lunates with abrupt retouch (Valla, 1984; Bar-Yosef and Valla 1979).
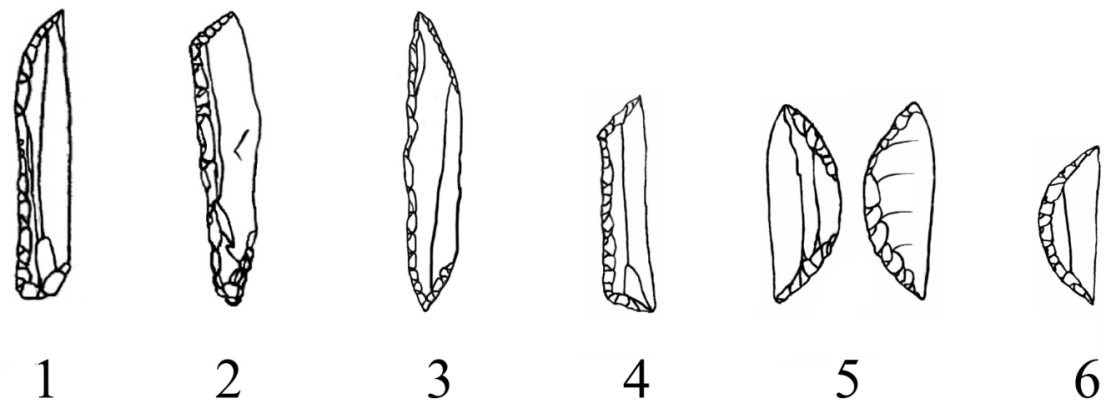

4

5

6

The emergence of the Natufian culture was marked by the establishment of permanent settlements and broadening of the diet including consumption of small game (the hunters' second- and third-choice prey), as well as greater reliance on vegetal food sources requiring considerable preparation (Stiner et al., 2000; BelferCohen and Bar-Yosef, 2000; Munro, 2004). Researchers explain this shift in subsistence and social organization as an adaptive response to a steady population increase during the preceding Geometric Kebaran when high population density and reduction in available territories made budding-off of daughter groups, practiced 
previously, no longer possible (Goring-Morris and Belfer-Cohen, 1998). The Late and Final Natufian witnessed additional changes in settlement and subsistence which involved reduced occupation density and a return to more mobile strategies while still exerting intense pressure on animal resources (Munro, 2004).

World-wide archaeological and ethnographical evidence show a range of designs of projectiles with microlithic inserts (Clark, 1969; Clark et al., 1974; Clark, 1977; Gvosdover, 1952; Leroi-Gourhan, 1983; Odell, 1978; Brooks and Wakankar, 1976; Garlake, 1987). In the Levant no complete or almost complete projectiles indicating design or mode of microlith hafting have been found. The evidence for the use of microliths as elements in projectile weapons in the region is limited to the occurrence of a Helwan lunate lodged in a vertebra of a human skeleton from the Early Natufian deposits of Kebara cave in Mount Carmel, Israel (Bocquentin and Bar-Yosef, 2004). In addition, macro- and micro-fractures diagnostic of projectile impact have been identified in low frequencies on microliths from Geometric Kebaran and Natufian sites (Anderson-Gerfaud, 1983; Valla, 1987; Shimelmitz et al., 2004; Yaroshevich, 2006; Richter, 2007; Marder et al., 2007; Valla, et al., 2007). On the basis of these studies, a variety of possible designs that could have been applied for projectiles composed of microliths during the period has been suggested.

The design of a projectile weapon may affect its performance characteristics. Therefore, reconstructing their design constitutes a necessary stage in studies intended to investigate the performance of these tools. Such reconstructions have been attempted in a few studies based on archery experiments involving microliths hafted as projectile inserts in different modes and investigation of projectile damage patterns on experimental and archaeological microliths (Nuzhnyy, 1990, 1993, 1999; Crombe at al., 2001). These studies indicated a connection between temporal change in microlithic variability and transformations in the design of projectile weapons during the Upper Paleolithic and Mesolithic in Europe.

The present study combines archery experiments using replicas of the main microlith types of the Levantine Epipaleolithic and a comparative analysis of archaeological trapeze/rectangles and lunates - types of microliths most characteristic for the Geometric Kebaran and the Natufian, respectively. It is important to emphasize that our analytical approach and findings do not rule out the evidence that there were additional uses of microliths during the Epipaleolithic (see Richter, 2007 and references therein). Our experimental arrowheads were assembled with the aim of representing a wide range of arrow designs involving different hafting modes of the microlithic inserts, i.e. as leading tips and as side elements positioned in various angles relative to the arrow shaft. The experiments had several goals: first, to reveal damage patterns indicating mode of microlith hafting; second, to compare performance characteristics of the arrows with different designs and composed of different types of microliths; third, to provide a means for evaluating the frequency of projectile damage expected to be found in assemblages recovered from archaeological sites, i.e. a taphonomic analysis of microlithic projectile implements. Following the initial experimental stage of the research, we recorded patterns of impact damage on Geometric Kebaran and Natufian samples with the aim of 
reconstructing design of projectiles fitted with microliths characteristic for each of these cultures and detecting possible changes in projectile weapon technology through time.

Experimental studies with Levantine microliths have not been performed before. Moreover, the present study, for the first time, combines performance analysis of differently designed arrows with the investigation of damage patterns involving different microlith types hafted in a variety of modes. The experimentally based investigation of interaction between temporal change in microlith morphology and design and functioning of microlith implemented projectiles during the Late Pleistocene will provide more insights into the nature of cultural changes during the period preceding the most important social and economic shift in human history - the transition to agriculture in the Levant.

\section{Materials and methods}

\subsection{Background}

Experimental studies with different flint projectile elements have provided descriptions of a variety of fracture types resulting from projectile impact (Fischer et al., 1984, Barton and Bergman, 1982; Bergman and Newcomer, 1983; Moss and Newcomer, 1982; Odell and Cowan, 1986; Nuzhnyy, 1989, 1990, 1993, 1999; Cattelain and Perpère, 1994; Caspar and De Bie, 1996; Crombe at al., 2001; Shea, 1988; Lombard and Pargetter, 2008). The terminology of damage most commonly used in describing fractures resulting from projectile impact was developed through the experimental study of Fisher et al., (1984) based on the morphology of fracture initiation and termination as seen in profile (Ho-Ho classification, Hayden, 1979). Fisher et al., (1984) determined that two types of fractures can be recognized as diagnostic of projectile impact, i.e., fracture types that could not have been produced as a result of other activities or as a result of production accident or trampling. The first type, the step terminating bending fracture has a smooth initiation which lacks a negative of bulb of percussion, continues parallel to the point's surface and terminates abruptly in a right angle break. The smooth initiation (bending) indicates forces distributed over a large area as opposed to forces applied at a particular point when cone initiating fracture occurs (fracture with a concave profile as a result of the presence of a negative of a bulb of percussion). The second type, spin-off, is a secondary cone initiating fracture which originates on the surface of a bending fracture. Spin-off fractures occur when already broken pieces of the flint projectile element are pressed together as a result of kinetic energy stored in the shaft during impact. Spin-off is considered as diagnostic of projectile impact relative to the size of the flint insert. For microlithic inserts a spin-off of $1 \mathrm{~mm}$ length is considered as diagnostic of projectile impact, as shown by experimental results (Fischer et al., 1984).

Experimental studies also determined microscopic damage indicating projectile impact. These are linear polishes and striations (Fischer et al., 1984; Moss and Newcomer, 1982; Crombe et al., 2001). The striations appear when microscopic 
pieces of flint, removed during impact, scratch the point's surface. The direction of the micro-fractures corresponds to the direction of arrow movement.

Experiments have further shown that macro-fractures diagnostic of projectile impact vary in terms of location of initiation and orientation. The most common projectile damage described in the experiments are bending and spin-off fractures that initiate either on a dorsal or ventral surface and continue parallel to the longitudinal axis of the point removing part of its surface or part of its lateral edge. This type of damage was observed on various types of straight points (Barton and Bergman, 1982; Bergman and Newcomer, 1983; Fischer et al., 1984; Nuzhnyy, 1990, 1993, 1999; Odell and Cowan, 1986; Geneste and Plisson, 1990; Caspar and De Bie, 1996; Crombe et al., 2001), on obliquely hafted macrolithic segments (Lombard and Pargetter, 2008), as well as on elongated narrow rectangles fitted as lateral blades (Nuzhnyy, 1990, 1993,1999).

Fractures initiating on the retouched edge of the microlith were defined as diagnostic of hafting the microlith as a straight point (Nuzhnyy, 1990). These fractures occur due to the asymmetry of microliths having one retouched lateral edge opposite an unmodified edge. This asymmetry causes a curved trajectory of the point inside the target toward the sharp edge of the microlith and leads subsequently to the breakage of the microlith from the retouched to the sharp edge.

Fractures initiating on a sharp edge were observed on experimental transversally hafted points (Fisher et al., 1984; Nuzhnyy, 1990, 1993; Lombard and Pargetter, 2008); on obliquely hafted points (Nuzhnyy, 1990, 1993; Lombard and Pargetter, 2008), as well as on side elements, i.e. lateral blades and barbs of the projectiles (Nuzhnyy, 1990, 1999; Crombe et al., 2001).

Experiments also indicated that mode of microlith hafting affects the frequency of projectile damage. For example, microliths hafted as barbs were damaged in low frequencies (about 5\%, Crombe et al., 2001) while the frequencies of macro-damage on projectile tips vary from 32\% (Crombe et al., 2001) to $41 \%$ (Fischer et al., 1984).

Fractures diagnostic of projectile impact have been observed on microliths from a number of Levantine Epipaleolithic sites and various hafting modes were suggested for different microlith types. Thus, the function as tips and lateral elements of projectiles was suggested for the trapeze/rectangles from the Geometric Kebaran sites Ein Miri (Shimelmitz, et al., 2004), Hefziba and Neve David (Yaroshevich, 2006). Fractures initiating on a sharp edge were observed on lunates from Natufian sites (Valla, 1987; Marder et al., 2007; Valla et al., 2007). Based on obliquely oriented macro-fractures initiating on the sharp edges of lunates from the Final Natufian site of Eynan (Ein Mallaha), it was suggested that they were hafted as oblique, rather than transversal points (Marder et al., 2007; Valla et al., 2007). Micro-fractures indicating projectile impact on lunates from the Late Natufian of Mureybet and Abu Hureyra allowed interpretation of their use as transversally and obliquely hafted points and barbs (Anderson-Gerfaud, 1983). Recent use-wear analysis of Natufian lithic assemblages indicated transversal hafting for several lunates from Hayonim Cave and as barbs from Salibiya I (Richhter, 2007). 


\subsection{Experiments}

2.2.1. Arrow design, modes of hafting and microlith types

For the present study 102 arrows were made incorporating a total of 265 microlith replicas prepared by Dodi Ben Ami. Commercially manufactured wooden shafts, 80 $\mathrm{cm}$ long and $9 \mathrm{~mm}$ in diameter were used for preparation of all arrows. Each arrow was fletched with three split duck feathers. In terms of hafting methods, the arrows can be divided into two groups. In the first, comprising 69 arrows, the microliths were hafted using adhesive, prepared by boiling a mixture of beeswax and resin with the addition of either gypsum powder or ochre powder as a filling. In certain cases a fiber binding was applied together with the adhesive. These arrows were prepared by Dmitri Nuzhnyy, and included the following designs which replicate ethnographic and archaeological examples as well as reconstructions suggested based on analysis of damage patterns.

1. Single straight points (Fig. 1b: 1, e.g. Odell, 1978) fitted with arch-backed bladelets $(\mathrm{N}=5)$ and trapeze/rectangles $(\mathrm{N}=7)$;

2. Single oblique points (Fig.1b: 2, e.g. Odell, 1978) fitted with arch-backed bladelets $(\mathrm{N}=3)$, Kebara points $(\mathrm{N}=2)$, trapeze/rectangles $(\mathrm{N}=10)$, Helwan lunates $(\mathrm{N}=4)$ and lunates with abrupt retouch $(\mathrm{N}=3)$;

3. Double oblique points (Fig. 1b: 3, e.g. Clark, 1977) fitted with Helwan lunates $(\mathrm{N}=4$,$) and with lunates with abrupt retouch (\mathrm{N}=4)$;

4. Single transversal points (Fig. 1b: 4, e.g. Clark, 1973) fitted with trapezes/rectangles $(\mathrm{N}=10)$, Helwan lunates $(\mathrm{N}=5)$ and lunates with abrupt retouch $(\mathrm{N}=5)$;

5. Arrows with oblique point and oblique barb attached to the shaft with its retouched edge (Fig. 1b: 5, e.g. Peterson, 1951) fitted with Helwan lunates $(\mathrm{N}=2)$ and lunates with abrupt retouch $(\mathrm{N}=1)$;

6. Self-pointed arrows with twisted barbs fitted with retouched bladelets with twisted lateral profile ( $\mathrm{N}=3$; Fig.1b: 6, e.g. Nuzhnyy, 1998). The barbs in these arrows were attached with their dorsal or ventral surface in contact with shaft;

7. Self-pointed arrow with lateral blades $(\mathrm{N}=1 \mathrm{~b}$ : 7; Fig. 1g, e.g. Gvosdover, 1952; Leroi-Gourhan, 1978), fitted with trapeze/rectangles.

In the second group, prepared by Dodi Ben Ami, the microliths were hafted using fragments of reed and commercial water-based glue. The group included 33 arrows with the following designs:

1. Self-pointed arrow with trapeze/rectangles mounted as lateral blades;

2. Arrow with straight point and four obliquely hafted barbs, two on each side of the shaft (Fig. 1b: 8). Arrows with numerous barbs, possibly fitted with microliths often occur in rock art hunting scenes (e.g. Brooks and Wakankar, 1976). In our experimental arrows of this design microgravette points served as the tips, whereas the barbs consisted of various types of microliths: archbacked bladelets $(\mathrm{N}=4)$, Kebara points $(\mathrm{N}=9)$, trapeze/rectangles $(\mathrm{N}=7)$, Helwan lunates $(\mathrm{N}=6)$ and lunates with abrupt retouch $(\mathrm{N}=6)$. The weight of 
arrows composed of one or two microliths was 20-25 gr., those with multiple elements was 35-40 gr.

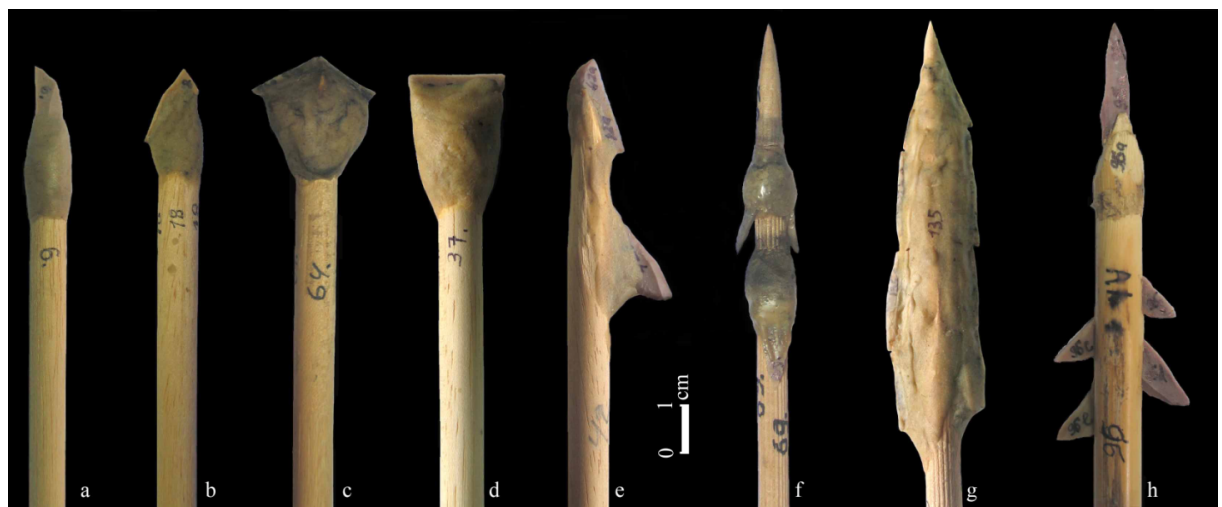

2.2.2. Shooting

The shooting, conducted in two sessions, was performed by Dmitry Nuzhnyy using a recurved wooden sport bow with plastic coating of $17.5 \mathrm{~kg}$ power. In the first session a freshly killed unskinned female goat was used as a target. A goat was selected as it closely resembles in size and anatomy gazelles, the most common prey for Epipaleolithic hunters (Bar-Oz, 2004 and references therein). During this session all the arrows of the first group were shot as was one arrow from the second group with a microgravette point and four Kebara points inserted as barbs. The session took place on Mount Carmel, Israel, in December 2006, with outside temperature of 15-17 ${ }^{\circ} \mathrm{C}$. The initial distance was $13 \mathrm{~m}$, after three hours the distance was reduced to $10 \mathrm{~m}$, and then reduced again to $8 \mathrm{~m}$ four hours after initiation of the session. This was done in order to minimize the influence of rigor mortis on the penetration abilities of the arrows. Each arrow was shot repeatedly until the microlith was either damaged or dislodged from the arrow.

For each shooting we recorded whether the arrow penetrated the target, ricocheted or missed the target. In the case of penetrating the target, the anatomical location and depth of arrow penetration were recorded. The location and condition of microliths were recorded after each shooting. The microlith could remain inside the target, remain in the arrow, or be dislodged outside, in each case either damaged or undamaged. When a microlith remained undamaged in an arrow, the arrow was shot again. In cases when two or more microliths composed the arrow, the arrow was retired if one of the microliths was either damaged or dislodged.

In the second session the target was a freshly purchased skinned sheep thorax encased in cardboard. All the arrows comprising the second group, except the one used in the first session, were shot in groups of ten from a distance of $5 \mathrm{~m}$. In this session only the number of trials for each arrow was recorded.

\subsection{Analyzed features}

\subsubsection{Performance characteristics}

We examined the influence of arrow design on penetrating abilities, durability and frequency of ricochets based on the sample of arrows shot in the first 
session. The penetrating ability represents the mean depth of target penetration. Durability was estimated based on two indices: The first, index 1 is the total number of shootings divided by the number of arrows. The second, index 2 is the number of penetrations divided by the number of arrows. The frequency of ricochets is the number of ricochets divided by number of ricochets and number of penetrations combined.

\subsubsection{Projectile damage analysis}

Following the shooting the microliths were cleaned and inspected for macrodamage. First, they were sorted into three groups: those with damage diagnostic of projectile impact, those with no diagnostic damage and those with no macro-damage at all. Then, the fractures diagnostic of projectile impact were classified according to the location of fracture initiation and its direction relative to the longitudinal axis of the microlith. The frequency of projectile damage and the distribution of the different fracture types were recorded according to the mode of microlith hafting and type of microlith. A number of experimental microliths hafted in different modes were inspected for micro-damage using a scanning electron microscope (SEM).

\subsubsection{Taphonomy of projectile microlithic elements}

Projectiles are usually used outside the settlement area. Only a portion of microliths used in hunting activity is expected to be brought back to the site either inside the game or still embedded in the projectile shaft. In order to estimate the frequency of microliths with projectile fractures in archaeological assemblages we recorded, during the first session of the experiments, whether the microlith was recovered from the target, from the arrow or was dislodged, either as the result of missing the target or after removing the arrow from the target. We tabulated the frequencies of microliths with projectile damage according to the location of microlith recovery. These data form the basis of a preliminary taphonomic analysis of microlithic inserts and provide a means of estimating the frequency of microliths with projectile impact damage that may have been returned to the site following hunting missions.

\subsection{Archaeological material}

The analysis was conducted on two samples of archaeological microliths representing two succeeding Epipaleolithic cultures: the Geometric Kebaran site of Neve David and the Natufian site of el-Wad Terrace (Fig. 2). Both sites are located on the western slope of Mount Carmel at the opening of wadies onto the Mediterranean coastal plain (Kaufman, 1987; Weinstein-Evron et al., 2007). 


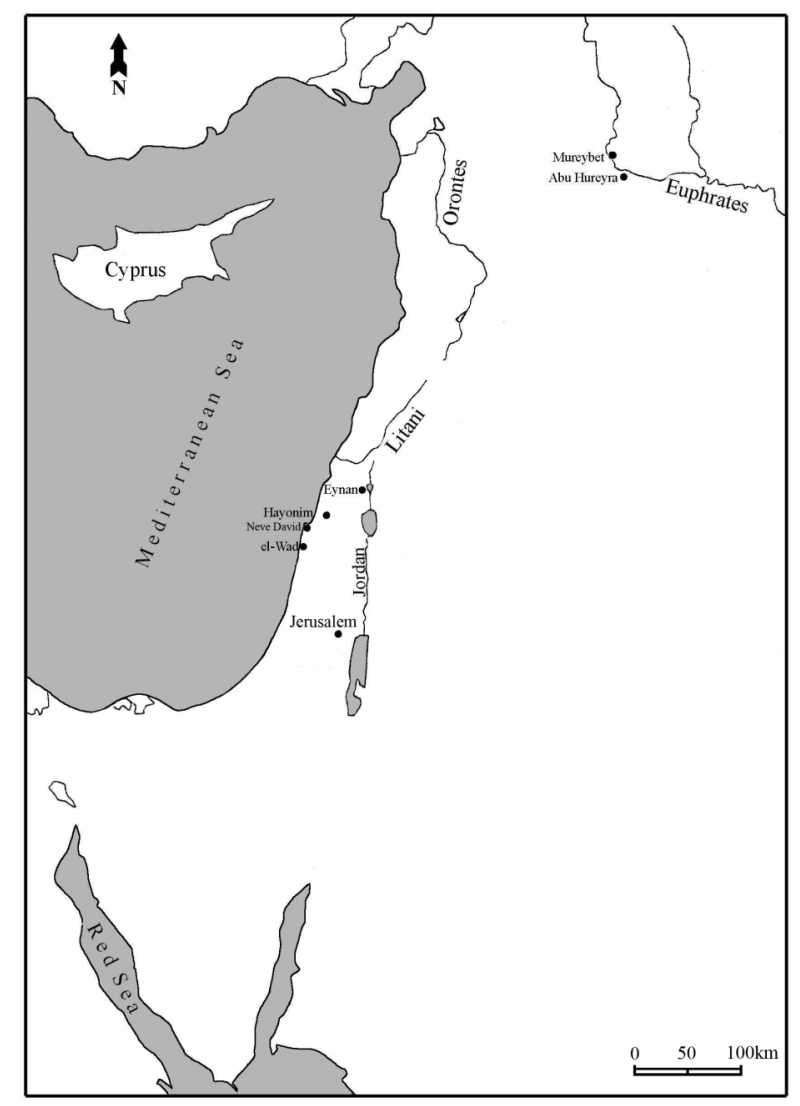

The sample from Neve David comprises all the trapezes/rectangles recovered from two $1 \mathrm{~m}^{2}$ excavation units $(\mathrm{N}=311)$. These include complete (possessing both truncations) and broken (possessing one truncation) backed microliths. In addition, 85 medial parts of backed microliths which may represent broken trapeze/rectangles or non-geometric microliths from the same units were added to the sample. The mean length of complete trapeze/rectangles from Neve David is $16.7 \mathrm{~mm}(\mathrm{SD}=2.6)$, mean width is $4.8 \mathrm{~mm}(\mathrm{SD}=0.6)$ and mean thickness is $1.8 \mathrm{~mm} \quad(\mathrm{SD}=0.4)$ (Yaroshevich, 2006).

The sample from el-Wad Terrace includes all 299 lunates recovered from two $1 \mathrm{~m}^{2}$ excavation units from deposits representing the Late Natufian and the upper part of the Early Natufian. The sample includes 182 Helwan lunates (22 of which have either alternating or inverse retouch) and 117 lunates with abrupt retouch. The average lengths, widths and thicknesses of Helwan lunates are $21.9 \mathrm{~mm}(\mathrm{SD}=4.6)$, $8.1 \mathrm{~mm}(\mathrm{SD}=1.4)$ and $2.9 \mathrm{~mm}(\mathrm{SD}=0.7)$. For the lunates with abrupt retouch the average lengths, widths and thickness are $16.9 \mathrm{~mm}(\mathrm{SD}=4.4), 6.5 \mathrm{~mm}(\mathrm{SD}=1.9)$ and $2.4 \mathrm{~mm}(\mathrm{SD}=0.5)$, respectively (Liber, 2006). 
In addition to the macro-fracture analysis performed on all the archaeological microliths, three trapeze/rectangles from Neve David and seven lunates from el-Wad Terrace were observed through SEM.

\section{Results}

\subsection{Experimental data}

\subsubsection{Arrow Performance}

Table 1 presents the performance characteristics of differently designed arrows. In terms of penetrating abilities, oblique points $(23.0 \mathrm{~cm}$ penetration depth), transversal points $(22.6 \mathrm{~cm})$ and self-pointed arrows with lateral blades $(22.5 \mathrm{~cm})$ yielded the highest values. Much lower values averaging $15.0 \mathrm{~cm}, 11.0 \mathrm{~cm}$ and 11.5 $\mathrm{cm}$ showed straight points, double oblique points and the arrow with a microgravette point and four oblique barbs, respectively. The lowest values showed self pointed arrows with twisted barbs: $5.6 \mathrm{~cm}$. The arrow composed of an oblique point and oblique barb penetrated once to the considerable depth of $43 \mathrm{~cm}$.

\begin{tabular}{|c|c|c|c|c|c|c|c|c|}
\hline Arrow design & $\begin{array}{c}\mathrm{N} \text { target } \\
\text { penetrati } \\
\text { ons }\end{array}$ & $\begin{array}{c}\mathrm{N} \\
\text { Rico } \\
\text { chets }\end{array}$ & $\begin{array}{c}\mathrm{N} \\
\text { missing } \\
\text { target }\end{array}$ & $\begin{array}{c}\text { Total N } \\
\text { shooting } \\
\text { S }\end{array}$ & $\begin{array}{l}\text { Mean } \\
\text { depth }\end{array}$ & $\begin{array}{c}\text { Index } \\
1\end{array}$ & $\begin{array}{c}\text { Index } \\
2\end{array}$ & $\begin{array}{l}\text { Ricoch } \\
\text { et } \\
\text { ratio }\end{array}$ \\
\hline Straight points $\mathrm{N}=12$ & 15 & 2 & 14 & 31 & 15.0 & 2.6 & 1.4 & 11.8 \\
\hline Oblique points $\mathrm{N}=22$ & 23 & 2 & 24 & 49 & 23 & 2.2 & 1.1 & 8.0 \\
\hline Double oblique $\mathrm{N}=8$ & 11 & 11 & 7 & 29 & 11.0 & 3.6 & 1.4 & 50.0 \\
\hline Transversal points $\mathrm{N}=20$ & 35 & 10 & 15 & 60 & 22.6 & 3.0 & 1.75 & 22.2 \\
\hline Oblique point with oblique barb $\mathrm{N}=3$ & 1 & - & 4 & 5 & 43 & 1.7 & 0.3 & - \\
\hline $\begin{array}{l}\text { Straight point with four oblique barbs } \\
N=1\end{array}$ & 1 & - & - & 1 & 11.5 & 1.0 & 1.0 & - \\
\hline Self-pointed with twisted barbs $\mathrm{N}=3$ & 6 & - & 7 & 13 & 5.6 & 4.3 & 2.0 & - \\
\hline Self-pointed with lateral blades $\mathrm{N}=1$ & 2 & - & 1 & 3 & 22.5 & 3 & 2.0 & - \\
\hline
\end{tabular}

Table 1: Performance characteristics of arrows shot in the first session.

The highest durability indices among arrows with microlithic tips occurred on double points and transversal points. The mean numbers of shootings per arrow (Index 1) were 3.6 and 3.0 and the mean numbers of target penetrations (Index 2) were 1.4 and 1.8 for double oblique points and transversal points, respectively. Selfpointed arrows also showed high values of durability. Thus, the arrow with lateral blades was shot three times, with two of them resulting in target penetration; the arrows with twisted barbs were shot in average of 4.3 times with a mean value of target penetration of 2.0. Single straight points and oblique points showed considerably lower values with mean number of shootings of 2.6 and 2.2 and mean number of penetrations of 1.4 and 1.1 for straight and oblique points, respectively.

Ricochets were most common among double oblique points $(50 \%)$ whereas among straight and oblique points ricochets comprised $11.8 \%$ and $8 \%$ respectively. Transversal points are in a middle position with an average ricochet frequency of $22 \%$.

\subsubsection{Macro-fractures diagnostic of projectile impact}

Following the observations on the experimental microliths we classified the macro-fractures diagnostic of projectile impact according to their orientation and location of initiation. (Fig. 3). 


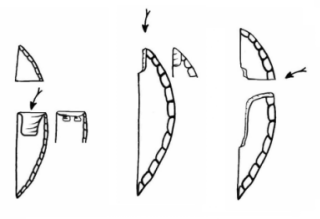

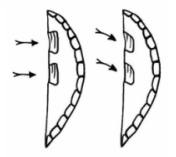

b1

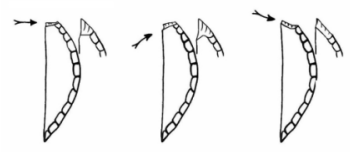

b2

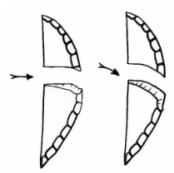

b3
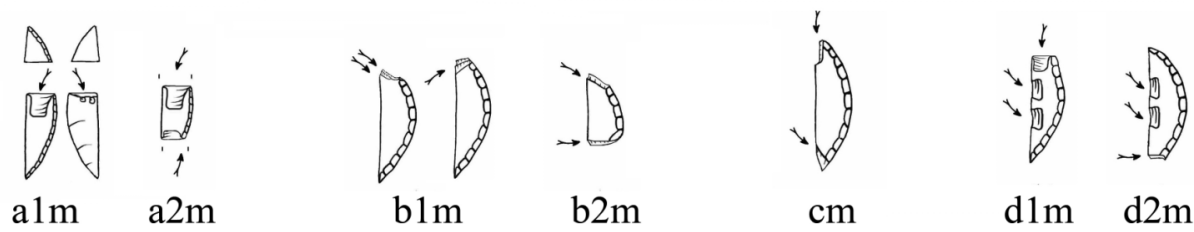

$\mathrm{cm}$

$\mathrm{d} 1 \mathrm{~m} \quad \mathrm{~d} 2 \mathrm{~m}$

Type a. Fractures oriented parallel to the longitudinal axis of the microlith:

1. Fractures initiating on microlith surface. These are step terminating bending fractures and spin-off fractures that initiate either on the dorsal or ventral surface of the microlith and continue parallel to its longitudinal axis removing part of the surface or part of the lateral edge of the microlith:

2. Fractures initiating on a retouched edge which remove only the tip of the microlith. These fractures can appear as step-terminating bending fractures that remove part of the dorsal or ventral surface or as burin-like fractures that remove part of the sharp edge.

3. Fractures initiating on a retouched edge that split the microlith across its body. These are bending initiating fractures that start at some point on the retouched edge of the microlith and continue parallel to its longitudinal axis, removing part of the sharp edge.

Type b. Fractures oriented obliquely or perpendicularly relative to the longitudinal axis of the microlith. All these fractures initiate on the sharp edge of the microlith. In an attempt to reveal the association between fracture orientation and mode of hafting we recorded more precisely the orientation of these fractures relative to the longitudinal axis of the microlith:

1. Fractures along a sharp edge. These are step-terminating bending fractures that remove part of the dorsal or ventral surface, oriented either obliquely or perpendicularly relative to the longitudinal axis of the microlith.

2. Fractures removing the tip of the microlith: these are stepterminating bending fractures or burin-like fractures that can be observed on either a dorsal or ventral surface of the microlith or in cross-section. These fractures are oriented either in a straight, sharp or blunt angle relative to the longitudinal axis of the microlith.

3. Fractures that split microlith across its body: bending initiating fractures that start at some point on the sharp edge and split the microlith into two (or more) parts. In a few cases spin-off fractures 
were observed on the surface of these bending fractures. Fractures across the microlith body were oriented either obliquely or perpendicularly relative to the longitudinal axis of the microlith. In the first case one of the broken parts has a sharp angle of the break while the other has a blunt angle.

Some of the microliths exhibited multiple fractures diagnostic of projectile impact. Multiple fractures were classified as follows:

Type am. Two parallel fractures:

1. On the same end (proximal or distal), appearing on both ventral and dorsal surfaces.

2. On opposite ends oriented one towards the other.

Type bm. Two perpendicular/oblique fractures:

1. On the same end, proximal or distal.

2. On both proximal and distal ends.

Type $\mathrm{cm}$. Parallel and perpendicular/oblique fractures on opposite ends:

Type $\mathrm{dm}$. Fracture along sharp edge (b1) and:

1. Parallel fracture.

2. Perpendicular/oblique fracture.

Table 2 shows the distribution of single fractures diagnostic of projectile impact according to the mode of microlith hafting and type of microlith. Fig. 4 shows the frequencies of single fracture types according to the mode of microlith hafting.

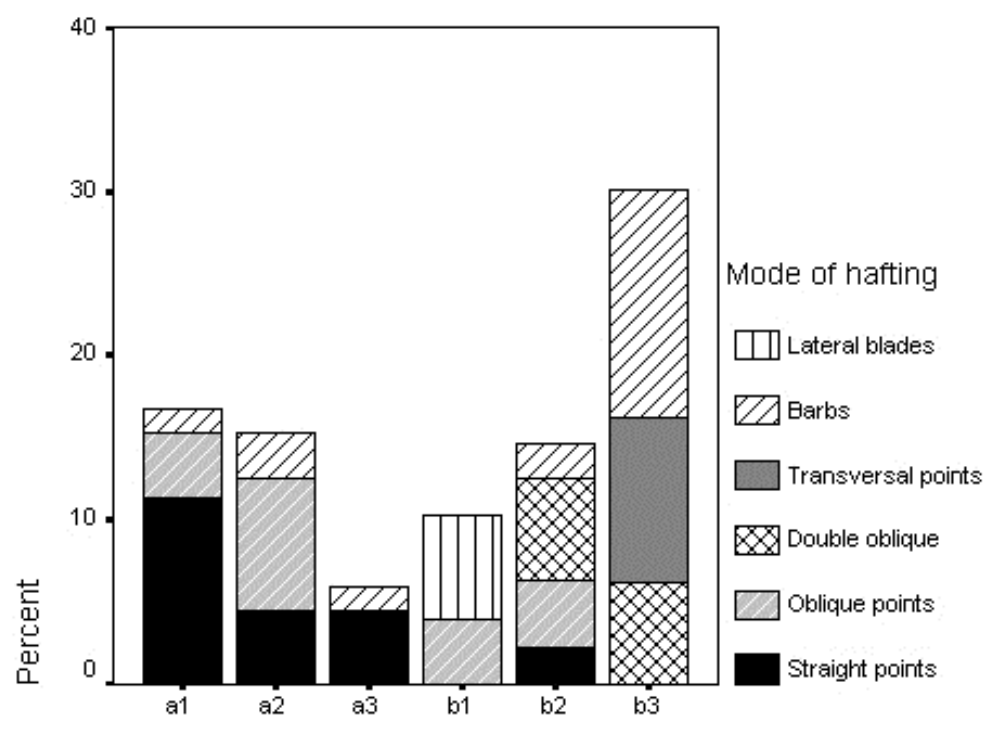

Single fracture type 


\begin{tabular}{|c|c|c|c|c|c|c|c|c|c|c|}
\hline \multirow{3}{*}{$\begin{array}{c}\text { Mode of } \\
\text { hafting }\end{array}$} & \multirow{3}{*}{ Type of microlith } & \multicolumn{3}{|c|}{ Parallel } & \multicolumn{6}{|c|}{ Oblique/perpendicular } \\
\hline & & \multirow[t]{2}{*}{ al } & \multirow[t]{2}{*}{$\mathrm{a} 2$} & \multirow[t]{2}{*}{ a3 } & $\mathrm{b} 1$ & \multicolumn{3}{|c|}{$\mathrm{b} 2$} & \multicolumn{2}{|c|}{ b3 } \\
\hline & & & & & Obliquely & $\begin{array}{l}\text { Sharp } \\
\text { angle }\end{array}$ & $\begin{array}{c}\text { Straight } \\
\text { angle }\end{array}$ & $\begin{array}{l}\text { Blunt } \\
\text { angle }\end{array}$ & $\begin{array}{c}\text { Obliq } \\
\text { uely }\end{array}$ & $\begin{array}{c}\text { Perpen } \\
\text { dicularly }\end{array}$ \\
\hline \multirow{3}{*}{$\begin{array}{l}\text { Straight } \\
\text { points }\end{array}$} & Arch-back. bladelet & 1 & & 1 & & & & & & \\
\hline & Trapeze & & 2 & & & 1 & & & & \\
\hline & Microgravette point & 4 & & 1 & & & & & & \\
\hline \multirow{3}{*}{$\begin{array}{l}\text { Oblique } \\
\text { points }\end{array}$} & Arch-back. bladelet & 1 & & & & & & & & \\
\hline & Trapeze & & 1 & & & 1 & & & & \\
\hline & Lunate abr. retouch & & 1 & & 1 & & & & & \\
\hline \multirow{2}{*}{$\begin{array}{l}\text { Double } \\
\text { oblique } \\
\text { points }\end{array}$} & Helwan lunate & & & & & & & & & \\
\hline & Lunate abr. retouch & & & & & & & 1 & & 1 \\
\hline \multirow{3}{*}{$\begin{array}{l}\text { Trans } \\
\text { versal } \\
\text { points }\end{array}$} & Trapeze & & & & & & & & & \\
\hline & Helwan lunate & & & & & & & & & \\
\hline & Lunate abr. retouch & & & & & & & & 1 & 1 \\
\hline \multirow[t]{6}{*}{ Barbs } & Arch-back. bladelet & & & & & & 1 & & 1 & 4 \\
\hline & Kebara point & & 1 & 2 & & & & & 2 & 2 \\
\hline & Trapeze & & 1 & & & & 1 & & 8 & \\
\hline & Helwan lunate & & & & & & & 1 & & \\
\hline & Lunate abr. retouch & & 2 & & & & & & & 3 \\
\hline & Retouched bladelets & 2 & & & & & & & & \\
\hline $\begin{array}{l}\text { Lateral } \\
\text { blades }\end{array}$ & Trapeze & & & & 1 & & & & & \\
\hline
\end{tabular}

Table 2: Distribution of single fractures diagnostic of projectile impact on the experimental microliths according to hafting mode and type of microlith. Microliths from both sessions are included.

Single fractures oriented parallel to the longitudinal axis and initiating on a dorsal or ventral surface (type a1) occurred mostly on straight points (Fig. 5a:1a). However, the same type occurred also on oblique points (Fig. 5b:1) and on twisted barbs (5a: 2c). Single parallel fractures initiating on a retouched edge and removing only the tip of the microlith (type a2) occurred on straight points, oblique points, as well as on barbs. In the cases of the barbs, these were the distal tips (those distant from the shaft) which exhibited parallel fractures indicating that the fractures were created as the result of removing the arrow from the target (Fig. 5b:9d). Single parallel fractures initiating on retouched edges across the microlith body (type a3) were observed on straight points (5a:3a), as well as on two of 144 barbs (Fig. $5 \mathrm{a}: 4 \mathrm{c}, \mathrm{d})$. Again, the location of the fractures on barbs indicates that they were created while removing the arrow from the target.

Various types of single oblique/perpendicular fractures initiating on a sharp edge (types b1, b2, b3) occurred on transversal points (Fig. 5b:6), double oblique points, barbs (Fig. 5b:10b, c), oblique points (Fig. 5b:3), and lateral blades. One of the lateral blades (Fig. 11a: g) received a distinctively deep, obliquely oriented fracture which removed a considerable part of its sharp edge (type b1). In one case 
an oblique fracture removing tip (type b2) occurred on straight point fitted with trapeze/rectangle.

In terms of the angle of the oblique/perpendicular fractures, it appears that fractures oriented obliquely to the longitudinal axis of the microlith are most common and occur on obliquely hafted points and barbs, on lateral blades, as well as on transversal points (Fig. 5b:3, 5, 6, 8; 10; Fig. 11a: g). Fractures oriented perpendicularly to the longitudinal axis of the microlith also occurred on microliths hafted obliquely as well as transversally. Moreover, the same microlith can exhibit obliquely and perpendicularly oriented fracture (Fig. 5b:8; 10a). Fractures removing a tip at a blunt angle appeared on double oblique points (Fig. 5b:4; 9a), on barbs and on lateral blades (Fig. 11a: c). 

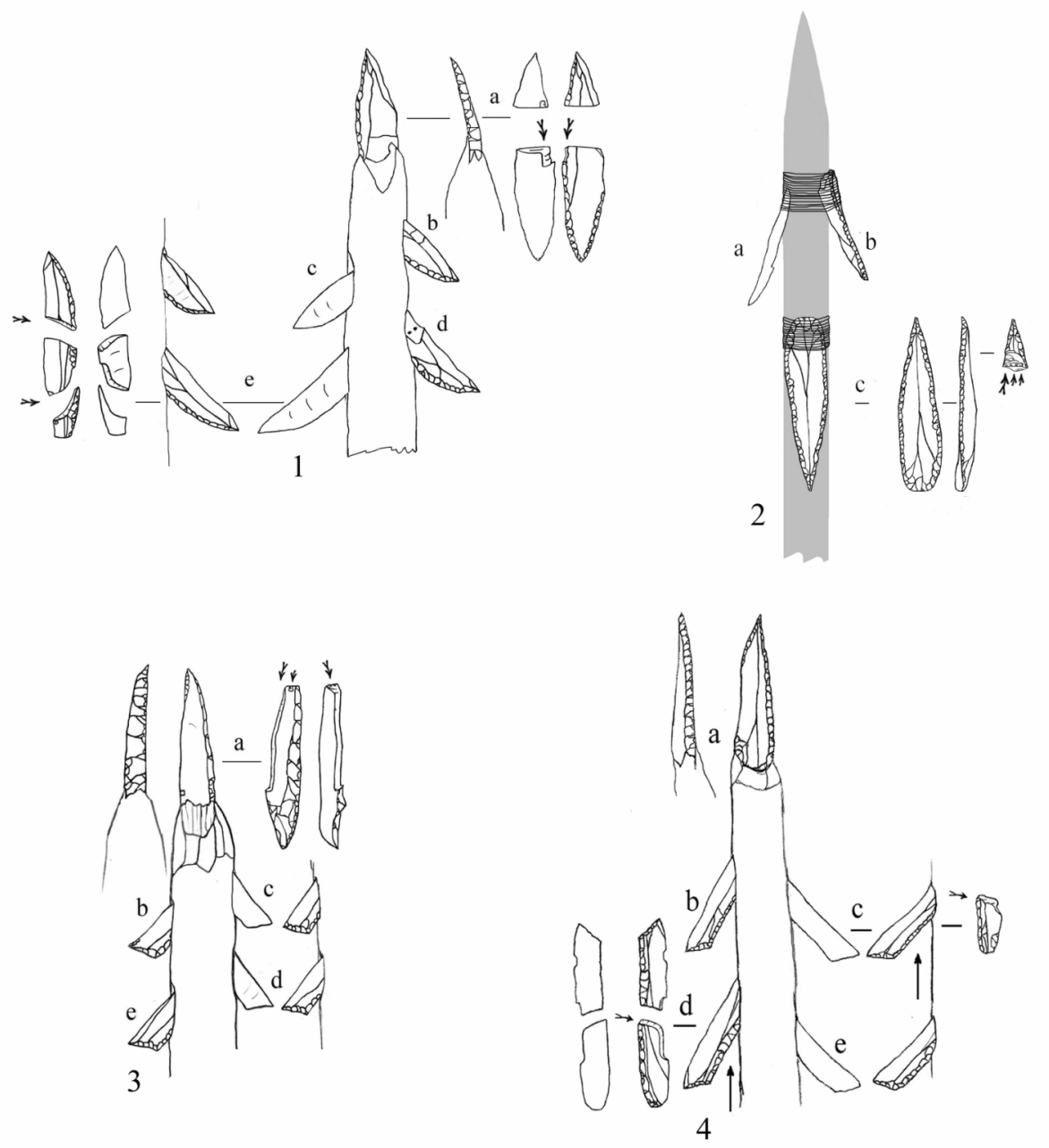

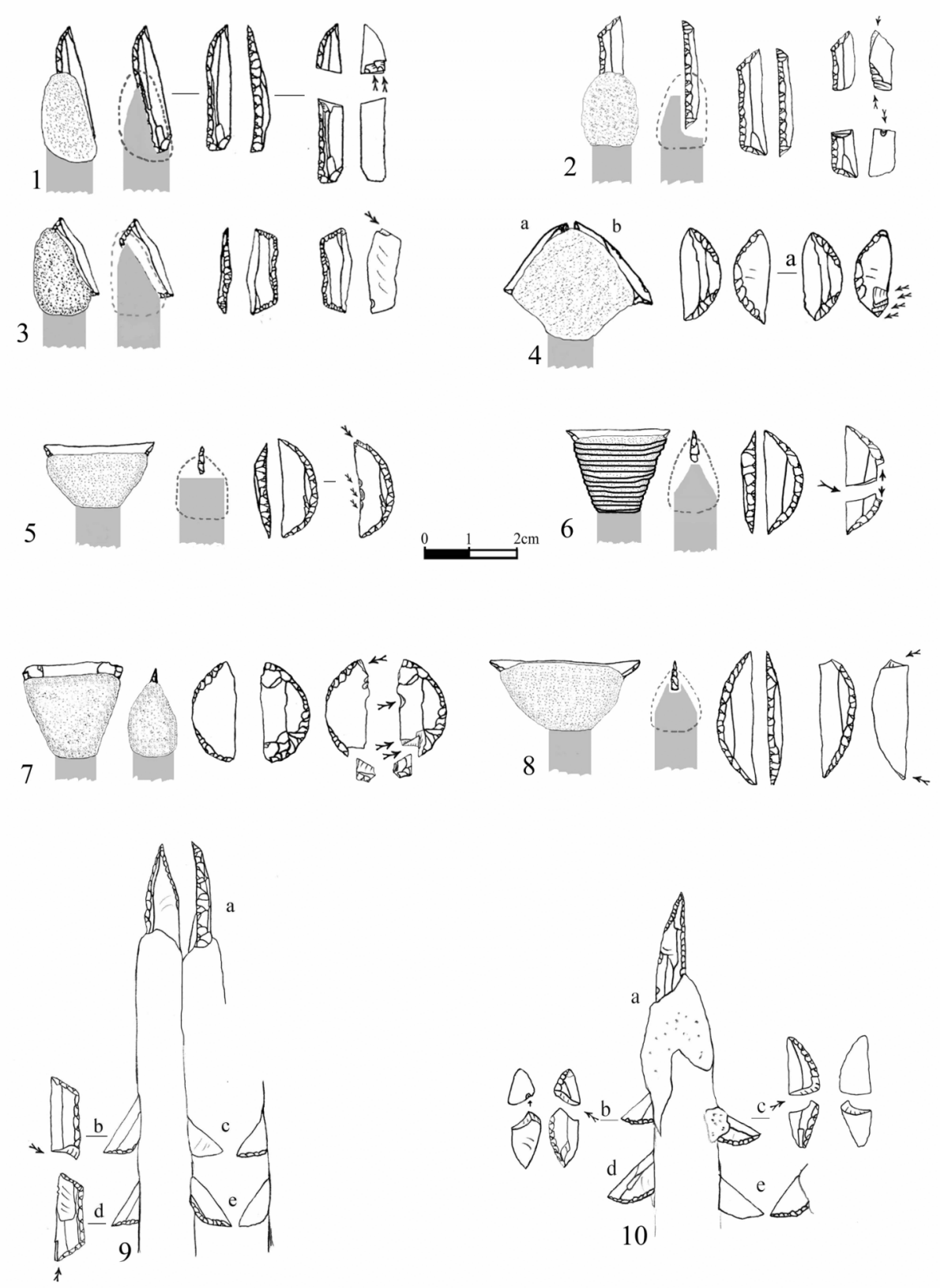


\subsubsection{Macro-fractures diagnostic of projectile impact and microlith morphology}

The influence of microlith morphology on the occurrence and distribution of diagnostic fracture types was approached in two ways. First, we examined whether different fracture types occurred on the same type of microlith when hafted in different modes. Second, we examined whether similar fracture types occurred on different types of microliths when hafted in the same manner.

In order to examine the effect of hafting mode on projectile damage we used the sample of trapeze/rectangles as they were hafted in all modes, except as double oblique points (Table 2). The distribution of fracture types on trapezes corresponds to the general pattern. When hafted as straight points they received mostly parallel fractures (Fig. 5b:2) whereas oblique/perpendicular fractures occurred on those hafted as transversal points (Fig. 9a), as barbs (Fig. 5b: 9b), and as lateral blades (Fig. 10a: e, g). Trapezes hafted as oblique points were subject to both parallel fractures and oblique/perpendicular fractures (Fig. 5b:3).

Barbs comprise the most appropriate sample for examining the influence of microlith morphology on projectile damage as all microlith types, with the exception of microgravette points, were hafted as barbs (Table 2). The majority of barbs with diagnostic fractures (26 of 34) exhibited oblique/perpendicular fractures initiating on a sharp edge regardless of the type of microlith (Fig. 5b: 9b; 10b,c). The rest of the barbs show parallel fractures. Among these, burin-like fractures removing the distal tip (type a2) appeared on lunates, trapeze/rectangles (Fig.5b:9d) and on one Kebara point. Fractures initiating on a retouched edge across the microlith body (type a3) occurred only on Kebara points, most probably as the result of the considerable length of the exposed portion of the barb (Fig. 5a: 4d,c). Parallel fractures initiating on a dorsal/ventral surface (type a1) occurred only on twisted barbs attached with their dorsal or ventral surface in contact with the shaft (Fig. 5a: 2c).

When comparing between trapeze/rectangles and lunates hafted as transversal points, differences in terms of severity of damage were noted, although both types of microliths exhibited similar diagnostic fractures. Two trapeze/rectangles were split into three and four pieces with diagnostic and non-diagnostic fractures (Fig. 9a), while three others were split into two pieces. Transversally hafted lunates were either split into two pieces (Fig.5b: 6) or received minimal damage, such as burin-like fractures on their tips and fractures along a sharp edge (Fig. 5b: 5, 7, 8). In other words, cases of more severe damage for transversal points occurred among trapeze/rectangles, whereas minimal damage occurred on lunates. 


\subsubsection{Multiple macro-fractures}

Table 3 shows the distribution of multiple fracture types according to the mode of microlith hafting and microlith type. The frequencies of multiple fractures according to the mode of hafting are summarized in Fig. 6.

\begin{tabular}{|c|c|c|c|c|c|c|c|c|c|}
\hline \multirow{2}{*}{$\begin{array}{l}\text { Mode of } \\
\text { hafting }\end{array}$} & \multirow{2}{*}{ Type of microlith } & \multirow[t]{2}{*}{$\mathrm{a} 1 \mathrm{~m}$} & \multirow[t]{2}{*}{$\mathrm{a} 2 \mathrm{~m}$} & \multicolumn{2}{|c|}{$\mathrm{b} 1 \mathrm{~m}$} & \multirow[t]{2}{*}{$\mathrm{b} 2 \mathrm{~m}$} & \multirow[t]{2}{*}{$\mathrm{cm}$} & \multirow[t]{2}{*}{$\mathrm{d} 1 \mathrm{~m}$} & \multirow[t]{2}{*}{$\mathrm{d} 2 \mathrm{~m}$} \\
\hline & & & & sharp & blunt & & & & \\
\hline \multirow{3}{*}{$\begin{array}{l}\text { Straight } \\
\text { points }\end{array}$} & Arch-backed bladelet & & 1 & & & & & & \\
\hline & Trapeze & & 1 & & & & & & \\
\hline & Microgravette point & 2 & & & & & & 1 & \\
\hline \multirow{3}{*}{$\begin{array}{l}\text { Oblique } \\
\text { points }\end{array}$} & Arch-back. bladelet & & & & & & & & \\
\hline & Trapeze & & & & & & & 1 & \\
\hline & Lunate abr. retouch & & & & & & & & \\
\hline \multirow{2}{*}{$\begin{array}{l}\text { Double } \\
\text { oblique } \\
\text { points }\end{array}$} & Helwan lunate & & & & 1 & & 1 & & \\
\hline & Lunate abr. retouch & & & & & & & & \\
\hline \multirow{3}{*}{$\begin{array}{l}\text { Transversal } \\
\text { points }\end{array}$} & Trapeze & & & & & 1 & & & 1 \\
\hline & Helwan lunate & & & 1 & & 1 & & & \\
\hline & Lunate abr. retouch & & & & & 1 & & & 1 \\
\hline \multirow{6}{*}{ Barbs } & Arch-backed bladelet & & & & & 1 & & & \\
\hline & Kebara point & & & & & & & & 1 \\
\hline & Trapeze & & & & & & & & 1 \\
\hline & Helwan lunate & & & & & & & & \\
\hline & Lunate abrupt retouch & & & & & & & & \\
\hline & Retouched bladelets & & & & & & & & \\
\hline $\begin{array}{l}\text { Lateral } \\
\text { blades }\end{array}$ & Trapeze & & & & & & & & 1 \\
\hline
\end{tabular}

Table 3: Distribution of multiple fracture types among experimental microliths according to hafting mode and type of microlith. Microliths from both sessions are counted. 


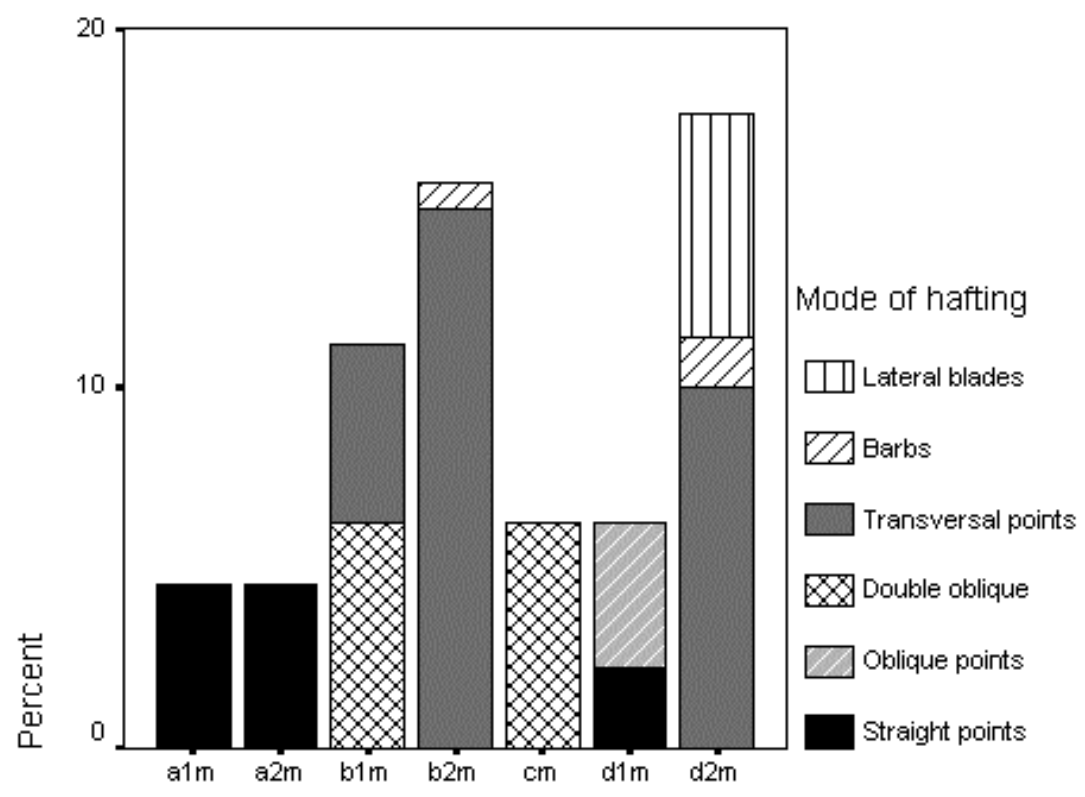

Multiple fracture type

Multiple parallel fractures, either bifacial on the same end (type a1m) or on both ends directed one towards the other (type a $2 \mathrm{~m}$ ) occurred only on straight points (Fig. 7a; 5b:2). Multiple fractures on the same tip (type b1m) occurred on a transversal point and a double oblique point on the tip opposite to the tip that hit the target (Fig, 5b:4).

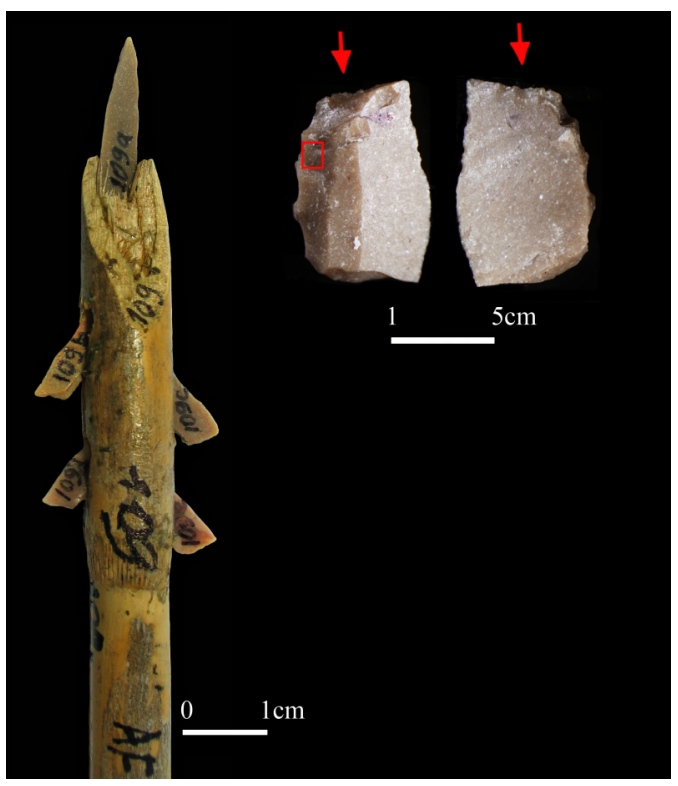


However, the angle of the fractures relative to the longitudinal axis of the microlith differs in the two cases. On the transversal point the fractures are oriented perpendicularly or in sharp angle whereas on the double oblique point the fractures are oriented in a blunt angle. Fractures initiating on sharp edge on both ends of the microlith on transversal points (Fig. 5b:7, 8) and on one barb from a total 144 barbs shot in the experiments (Fig. 5a:1e). This barb was fitted with arch-backed bladelet and we believe that the double breakage occurred due to the considerable length of the protruding part of the microlith.

The combination of parallel and oblique fractures on opposite ends of the microlith (type $\mathrm{cm}$ ) occurred on one lunate hafted as a double oblique point for which the tip that hit the target was removed with a parallel fracture (type a2) whereas the opposite tip was removed with an oblique fracture oriented in a blunt angle (type b2, Fig. 9a).

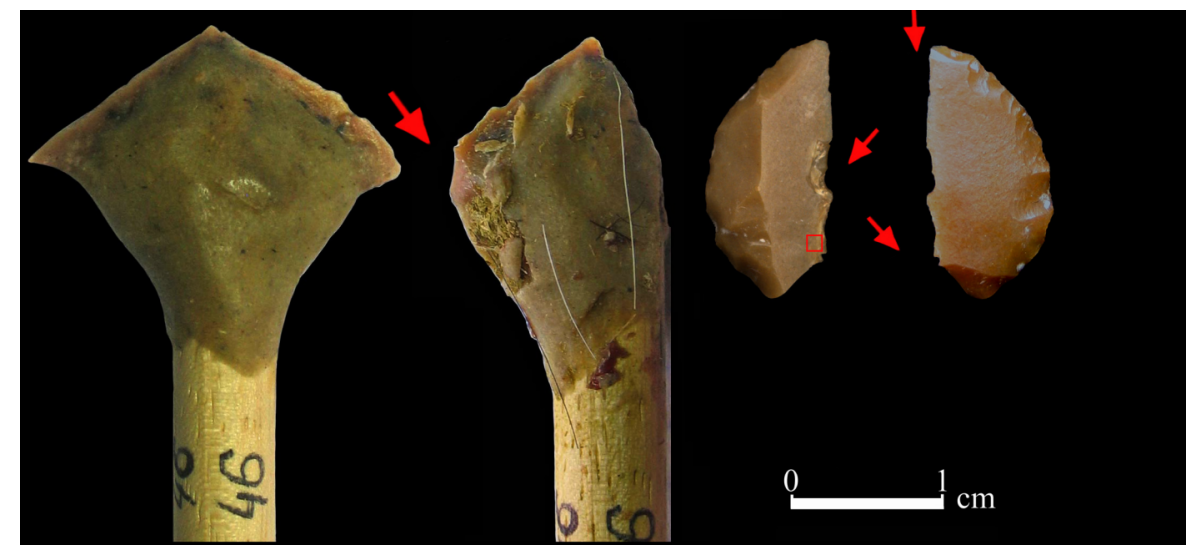

Fractures along a sharp edge in conjunction with parallel fractures (type $\mathrm{d} 1 \mathrm{~m}$ ) occurred on straight and oblique points. Fractures along a sharp edge in conjunction with other types of oblique/perpendicular fractures (type $\mathrm{d} 2 \mathrm{~m}$ ) occurred on a transversal point (Fig. 5b:5) and on a lateral blade (Fig. 10a:c). 


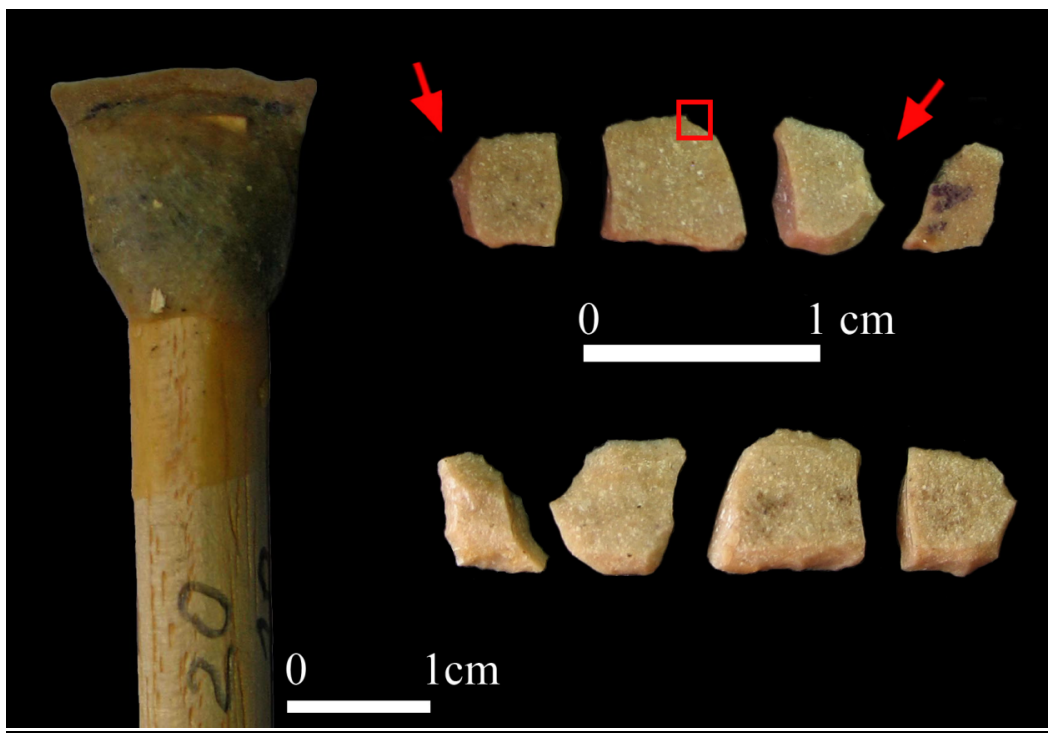

\subsubsection{Micro-fractures on the experimental microliths}

For the observations through SEM we chose eleven microliths with diagnostic macro-fractures. Linear micro-fractures were observed only on five of them, two microgravettes hafted as straight points (Fig. 7b), one transversally hafted trapeze/rectangle (Fig. 9b), one Helwan lunate hafted as a double oblique point (Fig.8b) and one trapeze/rectangle set as a lateral blade (Fig. 10b,c). Straight points, as well as lateral blades exhibited fractures oriented parallel to the longitudinal axis of the microlith, i.e. consistent with the hafting mode of the microlith and his direction during the impact. However, transversal points exhibited obliquely oriented striations whereas the lunate hafted as a double oblique point exhibited striations oriented roughly parallel to its longitudinal axis. In these cases the orientation of the micro-fractures is not consistent with the mode of microlith hafting which probably indicates the movement of the microlith from its original position during impact. 

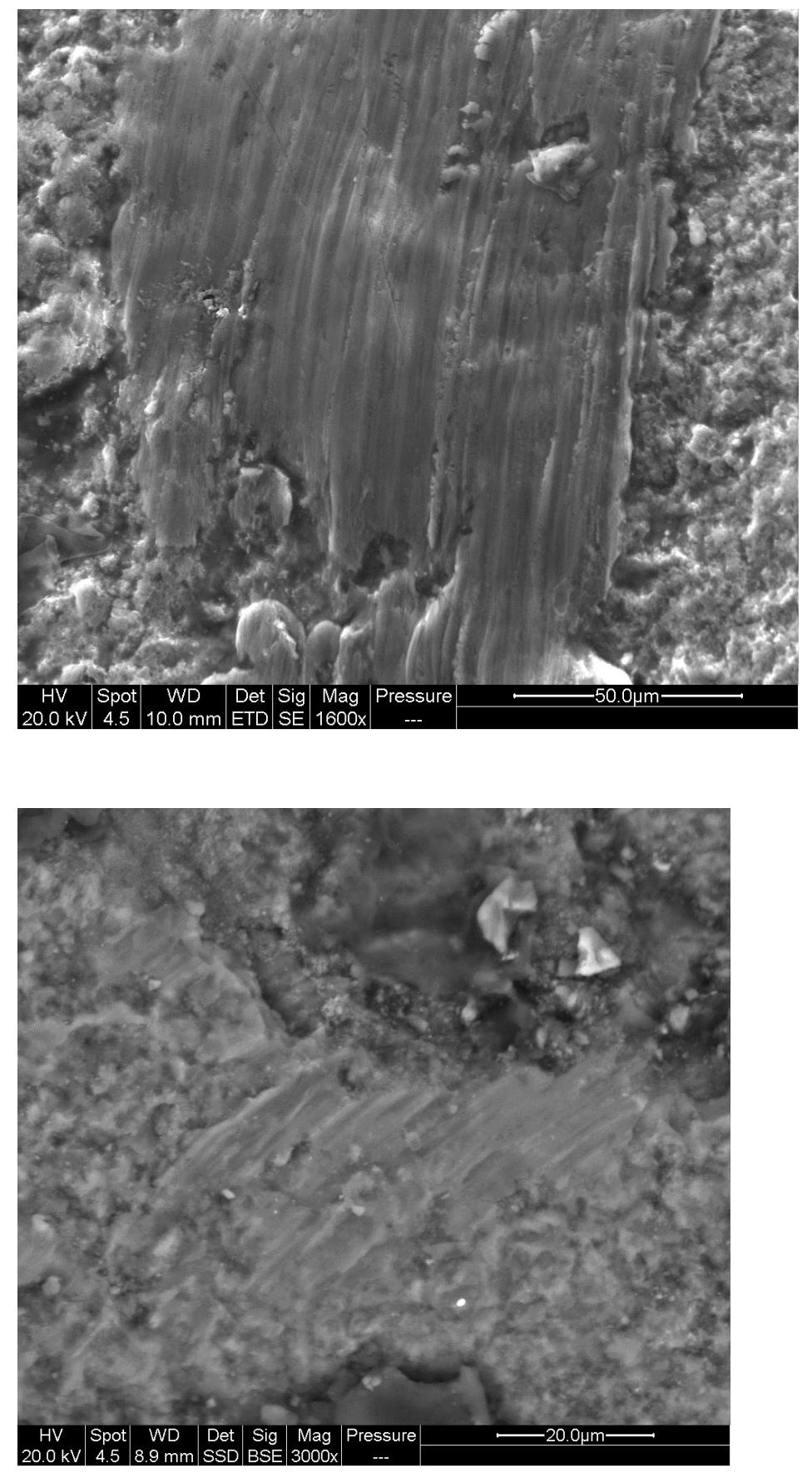

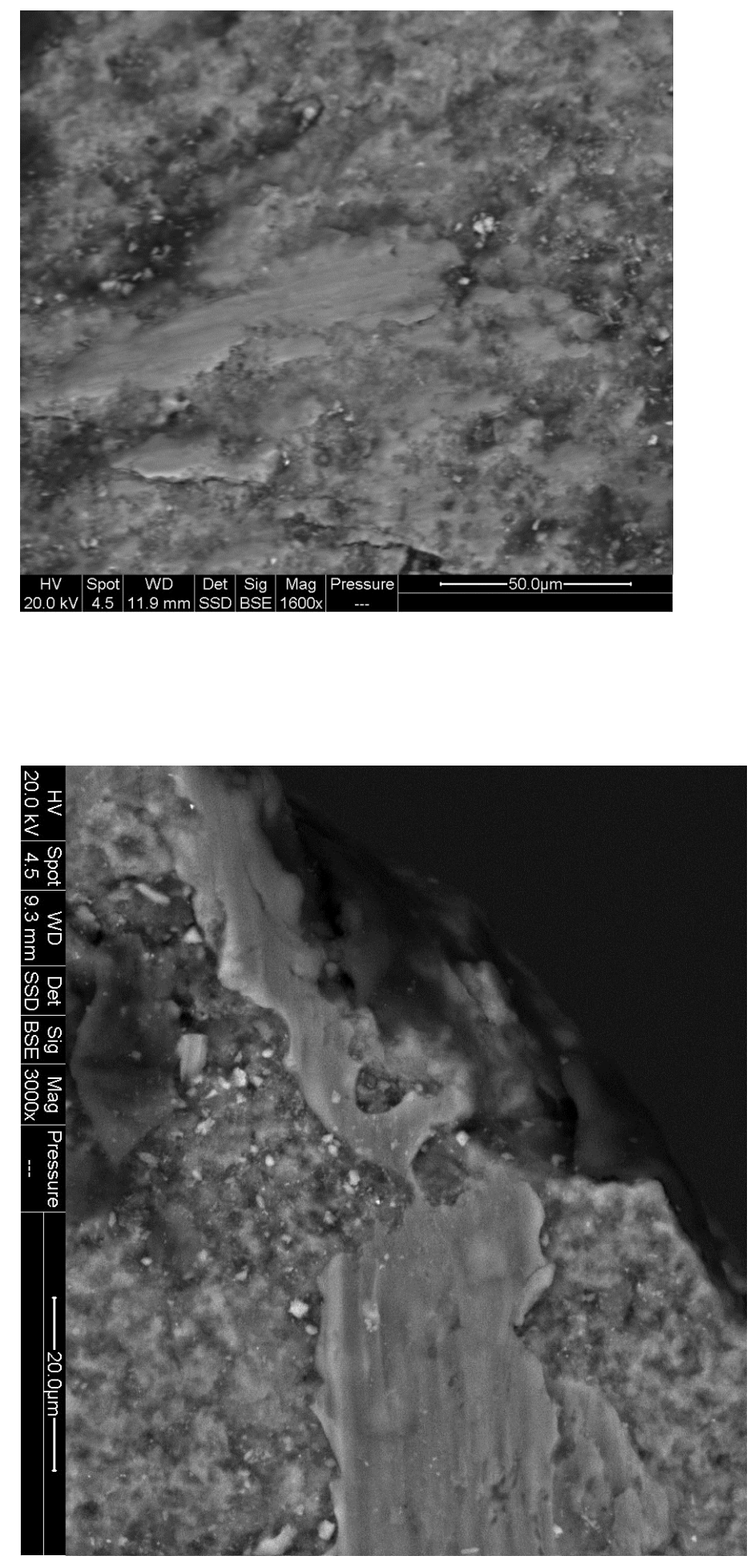
3.1.6. Frequencies of projectile macro-damage according to microlith type and mode of hafting

Tables 4 and 5 show the frequencies of diagnostic fractures according to mode of hafting and type of microlith for each shooting session separately.

\begin{tabular}{|c|c|c|c|c|c|c|c|c|c|c|c|}
\hline \multirow[t]{2}{*}{$\begin{array}{l}\text { Mode of } \\
\text { hafting }\end{array}$} & \multirow[t]{2}{*}{ Type of microlith } & \multicolumn{2}{|c|}{$\begin{array}{c}\text { Non- } \\
\text { diagnostic } \\
\text { damage }\end{array}$} & \multicolumn{2}{|c|}{$\begin{array}{l}\text { Diagnostic } \\
\text { projectile } \\
\text { damage }\end{array}$} & \multicolumn{2}{|c|}{$\begin{array}{c}\text { No } \\
\text { macro- } \\
\text { damage }\end{array}$} & \multicolumn{2}{|c|}{ Lost } & \multicolumn{2}{|c|}{ Total } \\
\hline & & $\mathrm{N}$ & $\%$ & $\mathrm{~N}$ & $\%$ & $\mathrm{~N}$ & $\%$ & $\mathrm{~N}$ & $\%$ & $\mathrm{~N}$ & $\%$ \\
\hline \multirow{4}{*}{$\begin{array}{l}\text { Straight } \\
\text { points } \\
\mathrm{N}=13\end{array}$} & $\begin{array}{l}\text { Arch-back. } \\
\text { bladelet }\end{array}$ & 2 & 40 & 3 & 60.0 & & & - & - & 5 & 100 \\
\hline & Trapeze/rectangle & 2 & 28.6 & 4 & 57.1 & 1 & 14. & - & - & 7 & 100 \\
\hline & $\begin{array}{l}\text { Microgravette } \\
\text { point }\end{array}$ & 1 & 100 & - & & & & - & - & 1 & 100 \\
\hline & Total & 5 & 38.5 & 7 & 53.8 & 1 & 7.7 & - & - & 13 & 100 \\
\hline \multirow{6}{*}{$\begin{array}{l}\text { Oblique } \\
\text { points } \\
\mathrm{N}=25\end{array}$} & $\begin{array}{l}\text { Arch-back. } \\
\text { bladelet }\end{array}$ & - & - & 1 & 33.3 & 1 & 33.3 & 1 & 33.3 & 3 & 100 \\
\hline & Kebara point & 1 & 50.0 & - & - & - & - & 1 & 50.0 & 2 & 100 \\
\hline & Trapeze/rectangle & 2 & 20.0 & 3 & 30.0 & 2 & 20.0 & 3 & 30.0 & 10 & 100 \\
\hline & Helwan lunate & 1 & 16.7 & - & - & 2 & 33.3 & 3 & 50.0 & 6 & 100 \\
\hline & $\begin{array}{l}\text { Lunate abr. } \\
\text { retouch }\end{array}$ & - & - & 2 & 50.0 & 1 & 25.0 & 1 & 25.0 & 4 & 100 \\
\hline & Total & 4 & 16.0 & 6 & 24.0 & 6 & 24.0 & 9 & 36.0 & 25 & 100 \\
\hline \multirow{3}{*}{$\begin{array}{l}\begin{array}{l}\text { Double } \\
\text { oblique } \\
\text { points } \\
\mathrm{N}=16\end{array}\end{array}$} & Helwan lunate & - & - & 2 & 25.0 & 4 & 50.0 & 2 & 25.0 & 8 & 100 \\
\hline & $\begin{array}{l}\text { Lunate abr. } \\
\text { retouch }\end{array}$ & 1 & 12.5 & 2 & 25.0 & 3 & 37.5 & 2 & 25.0 & 8 & 100 \\
\hline & Total & 1 & 6.3 & 4 & 25.0 & 7 & 43.8 & 4 & 25.0 & 16 & 100 \\
\hline \multirow{4}{*}{$\begin{array}{l}\text { Transversal } \\
\text { points } \\
\mathrm{N}=20\end{array}$} & Trapeze/rectangle & 3 & 30.0 & 2 & 20.0 & 2 & 20.0 & 3 & 30.0 & 10 & 100 \\
\hline & Helwan lunate & - & - & 2 & 40.0 & 1 & 20.0 & 2 & 40.0 & 5 & 100 \\
\hline & $\begin{array}{l}\text { Lunate abr. } \\
\text { retouch }\end{array}$ & - & - & 4 & 80.0 & - & & 1 & 20.0 & 5 & 100 \\
\hline & Total & 3 & 15.0 & 8 & 40.0 & 3 & 15.0 & 6 & 30.0 & 20 & 100 \\
\hline \multirow{5}{*}{$\begin{array}{l}\text { Barbs } \\
N=20\end{array}$} & Kebara point & 2 & 50.0 & 1 & 25.0 & - & & 1 & 25.0 & 4 & 100 \\
\hline & Helwan lunate & 1 & 33.3 & 1 & 33.3 & 1 & 33.3 & - & - & 3 & 100 \\
\hline & $\begin{array}{l}\text { Lunate abr. } \\
\text { retouch }\end{array}$ & - & - & - & - & 1 & 100. & - & - & 1 & 100 \\
\hline & $\begin{array}{l}\text { Retouched } \\
\text { bladelets }\end{array}$ & 2 & 16.7 & 2 & 16.7 & 3 & 25.0 & 5 & 41.7 & 12 & 100 \\
\hline & Total & 5 & 25.0 & 4 & 20.0 & 5 & 25.0 & 6 & 30.0 & 20 & 100 \\
\hline \multirow{2}{*}{$\begin{array}{l}\text { Lateral } \\
\text { blades } \mathrm{N}=8\end{array}$} & Trapeze/rectangle & 2 & 25.0 & - & - & 6 & 75.0 & - & - & 8 & 100 \\
\hline & Total & 2 & 25.0 & - & - & 6 & 75.0 & - & - & 8 & 100 \\
\hline \multicolumn{2}{|c|}{ Total first session } & 20 & 19.6 & 29 & 28.4 & 28 & 27.5 & 25 & 24.5 & 102 & 100 \\
\hline
\end{tabular}


Table 4: First session: frequencies of diagnostic and non-diagnostic fractures, undamaged and lost microliths according to mode of hafting and microlith type.

\begin{tabular}{|c|c|c|c|c|c|c|c|c|c|c|c|}
\hline \multirow[t]{2}{*}{$\begin{array}{l}\text { Mode of } \\
\text { microlith } \\
\text { hafting }\end{array}$} & \multirow[t]{2}{*}{ Type of microlith } & \multicolumn{2}{|c|}{$\begin{array}{c}\text { Non- } \\
\text { diagnostic } \\
\text { damage }\end{array}$} & \multicolumn{2}{|c|}{$\begin{array}{c}\text { Diagnostic } \\
\text { projectile } \\
\text { damage }\end{array}$} & \multicolumn{2}{|c|}{$\begin{array}{l}\text { No macro- } \\
\text { damage }\end{array}$} & \multicolumn{2}{|c|}{ Lost } & \multicolumn{2}{|c|}{ Total } \\
\hline & & $\mathrm{N}$ & $\%$ & $\mathrm{~N}$ & $\%$ & $\mathrm{~N}$ & $\%$ & $\mathrm{~N}$ & $\%$ & $\mathrm{~N}$ & $\%$ \\
\hline \multirow{2}{*}{$\begin{array}{l}\text { Straight } \\
\text { points } \\
\mathrm{N}=31\end{array}$} & $\begin{array}{l}\text { Microgravette } \\
\text { point }\end{array}$ & 7 & 22.6 & 8 & 25.8 & 13 & 41.9 & 3 & 9.7 & 31 & 100 \\
\hline & Total & 7 & 22.6 & 8 & 25.8 & 13 & 41.9 & 3 & 9.7 & 31 & 100 \\
\hline \multirow{6}{*}{$\begin{array}{l}\text { Barbs } \\
N=124\end{array}$} & $\begin{array}{l}\text { Arch-back. } \\
\text { bladelet }\end{array}$ & 11 & 45.8 & 7 & 29.2 & 6 & 25.0 & - & - & 24 & 100 \\
\hline & Kebara point & 9 & 37.5 & 7 & 29.2 & 8 & 33.3 & - & - & 24 & 100 \\
\hline & Trapeze/rectangle & 6 & 21.4 & 11 & 39.3 & 11 & 39.3 & - & - & 28 & 100 \\
\hline & Helwan lunate & 3 & 12.5 & - & - & 21 & 87.5 & - & - & 24 & 100 \\
\hline & $\begin{array}{l}\text { Lunate abr. } \\
\text { retouch }\end{array}$ & 7 & 29.2 & 5 & 20.8 & 11 & 45.8 & 1 & 4.2 & 24 & 100 \\
\hline & Total barbs & 36 & 29.0 & 30 & 24.2 & 57 & 46.0 & 1 & .8 & 124 & 100 \\
\hline \multirow{2}{*}{$\begin{array}{l}\text { Lateral } \\
\text { blades } \\
\mathrm{N}=8\end{array}$} & Trapeze & 2 & 25.0 & 2 & 25.0 & 4 & 50.0 & - & - & 8 & 100 \\
\hline & $\begin{array}{l}\text { Total lateral } \\
\text { blades }\end{array}$ & 2 & 25.0 & 2 & 25.0 & 4 & 50.0 & - & - & 8 & 100 \\
\hline \multicolumn{2}{|c|}{ Total second session } & 65 & 24.5 & 69 & 26 & 102 & 38.5 & 29 & 10.9 & 265 & 100 \\
\hline
\end{tabular}

Table 5: Second session: frequencies of diagnostic and non-diagnostic fractures, undamaged and lost microliths according to mode of hafting and microlith type.

Considerable differences appear in the frequencies of projectile damage between microliths hafted in different modes, between microliths hafted in the same mode but in differently designed arrows and between different types of microliths hafted in the same mode. The highest frequency of projectile damage occurred among single straight points $(53.8 \%)$ and transversal points $(40 \%)$. Among lateral blades only two of the total 16 microliths shot in both sessions (tables 4 and 5) exhibited diagnostic projectile damage which comprises $12.5 \%$.

The frequency of projectile damage among straight points shot in the first session $(53.8 \%)$ is more than twice the frequency for straight points shot in the second session (25.8\%). This difference can be explained by different arrow designs as the straight points shot in the first session consisted of a single microlith and the arrows were shot until the point was damaged or dislodged. In the second group the straight points were inset into arrows which also held four barbs. In many of these cases the arrow was retired as a result of damaged or dislodged barb/s even though the point remained undamaged. The high frequency of undamaged straight points shot in the second session (41.9\%) as opposed to $7.7 \%$ of undamaged straight points shot in the first session supports this explanation.

Among barbs Helwan lunates showed the lowest frequency of damage, diagnostic as well as not diagnostic when $87 \%$ of them remained undamaged (Table 
5). Lunates with abrupt retouch and trapezes/rectangles hafted in the same mode showed considerably higher values of diagnostic and not diagnostic damage when undamaged remained $46 \%$ and $39 \%$, respectively. Barbs fitted with non-geometric microliths, arch-backed bladelets and Kebara points, received the highest frequencies of damage when undamaged remained only $25 \%$ and $33 \%$ of the barbs fitted with these types, respectively. These differences can be related to the length of the protruding part of the barbs and their morphology.

\subsubsection{Taphonomy of projectile microlithic elements}

Table 6 shows the distribution of experimental microliths shot in the first session according to location of their recovery. A considerable number of microliths $(24.5 \%)$ were lost during the experiments. Another $16.7 \%$ were dislodged from the shaft as a result of missing the target or after the arrow was removed from the target. Both these categories would be lost in a hunting situation. The remaining $58.8 \%$ of the microliths were recovered from the target or from the arrows. Microliths comprising these two categories could have been returned to the settlement site. Projectile damage among these two categories was observed on $7.9 \%$ and $18.6 \%$ of the microliths recovered from the target and the arrows, respectively (the counts include microliths broken on impact that were recovered partly from the target and partly from the arrow; partly from the target and partly dislodged; and partly from the arrow and partly dislodged).

\begin{tabular}{|l|c|c|c|c|c|c|c|c|c|c|}
\hline \multirow{2}{*}{$\begin{array}{c}\text { Location of microlith } \\
\text { recovery }\end{array}$} & \multicolumn{2}{|c|}{$\begin{array}{c}\text { Non- } \\
\text { diagnostic } \\
\text { damage }\end{array}$} & \multicolumn{2}{c|}{$\begin{array}{c}\text { Diagnostic } \\
\text { projectile } \\
\text { damage }\end{array}$} & \multicolumn{2}{c|}{$\begin{array}{c}\text { No macro- } \\
\text { damage }\end{array}$} & \multicolumn{2}{c|}{ Lost } & \multicolumn{2}{c|}{ Total } \\
\cline { 2 - 12 } & $\mathrm{N}$ & $\%$ & $\mathrm{~N}$ & $\%$ & $\mathrm{~N}$ & $\%$ & $\mathrm{~N}$ & $\%$ & $\mathrm{~N}$ & $\%$ \\
\hline From arrow & 6 & 5.9 & 15 & 14.7 & 15 & 14.7 & - & - & 36 & 35.3 \\
\hline From target & 8 & 7.8 & 5 & 4.9 & 4 & 3.9 & - & - & 17 & 16.7 \\
\hline Dislodged outside & 5 & 4.9 & 3 & 2.9 & 9 & 8.8 & - & - & 17 & 16.7 \\
\hline From arrow and target & - & - & 1 & 1.0 & - & - & - & - & 1 & 1.0 \\
\hline $\begin{array}{l}\text { From arrow and } \\
\text { dislodged }\end{array}$ & 1 & 1.0 & 3 & 2.9 & - & - & - & - & 4 & 3.9 \\
\hline $\begin{array}{l}\text { From target and } \\
\text { dislodged }\end{array}$ & - & - & 2 & 2.0 & - & - & - & - & 2 & 2.0 \\
\hline Lost & - & - & - & - & - & - & 25 & 24.5 & 25 & 24.5 \\
\hline Total & 20 & 19.6 & 29 & 28.4 & 28 & 27.5 & 25 & 24.5 & 102 & 100.0 \\
\hline
\end{tabular}

Table 6: Frequencies of diagnostic fractures among microliths shot in the first session according to the location of microlith recovery.

The extraordinary discovery at the Natufian site Wadi Hammeh 27 of a hunter-gatherer's toolkit (Edwards, 2007) is significant here. The kit included numerous complete lunates (interpreted as projectile tips), a bladelet core (of the same raw material as the lunates), a hammerstone, several small pebbles (interpreted as slingshot projectiles), some gazelle phalanges and a sickle. The occurrence of complete lunates and the core raises the possibility that projectile points damaged during the hunt could be readily replaced by spares carried by the hunter and further suggests that not all microliths that remained damaged in the arrow would be brought 
back to the site. Thus, the frequency of projectile damage expected to be found in the samples recovered from the settlement sites can be presented as a range with minimum value equal to the frequency of diagnostic projectile fractures among microliths recovered from the carcass $(7.9 \%)$ and the maximum value equal to the frequencies of projectile damage among microliths recovered from the carcass and from the arrows combined $(7.9+18.6=26.5 \%)$. These values are expected to vary according to the mode of hafting applied since hafting modes affect the frequency of projectile damage. Interestingly, four microliths were recovered from the target without any macro-damage at all. Two of them were hafted as transversal points, one as an oblique point and one as a double oblique point.

\subsection{Archaeological data}

3.2.1 Macro-fractures diagnostic of projectile impact

Table 7 shows the frequency of projectile impact damage in the two studied samples. Damage diagnostic of projectile impact occurred on 5.3\% of the microliths from the Geometric Kebaran site of Neve David and on $8.4 \%$ of the lunates from elWad Terrace.

\begin{tabular}{|c|c|c|c|c|c|c|c|c|c|}
\hline \multirow[t]{2}{*}{ Site } & \multirow[t]{2}{*}{ Microlith type } & \multicolumn{2}{|c|}{$\begin{array}{c}\text { Non- } \\
\text { diagnostic } \\
\text { damage } \\
\end{array}$} & \multicolumn{2}{|c|}{$\begin{array}{c}\text { Diagnostic } \\
\text { projectile } \\
\text { damage }\end{array}$} & \multicolumn{2}{|c|}{$\begin{array}{l}\text { No macro- } \\
\text { damage }\end{array}$} & \multicolumn{2}{|c|}{ Total } \\
\hline & & $\mathrm{N}$ & $\%$ & $\mathrm{~N}$ & $\%$ & $\mathrm{~N}$ & $\%$ & $\mathrm{~N}$ & $\%$ \\
\hline \multirow{3}{*}{$\begin{array}{l}\text { Neve } \\
\text { David }\end{array}$} & Trapeze/rectangle & 254 & 81.7 & 16 & 5.1 & 41 & 13.2 & 311 & 100.0 \\
\hline & Medial parts & 80 & 94.1 & 5 & 5.9 & - & - & 85 & 100.0 \\
\hline & Total & 334 & 84.3 & 21 & 5.3 & 41 & 10.4 & 396 & 100.0 \\
\hline \multirow{4}{*}{$\begin{array}{l}\text { el-Wad } \\
\text { Terrace }\end{array}$} & Helwan lunate & 135 & 84.4 & 15 & 9.4 & 10 & 6.3 & 160 & 100.0 \\
\hline & Lunate abr. etouch & 93 & 79.5 & 10 & 8.5 & 14 & 12.0 & 117 & 100.0 \\
\hline & Lunate varia & 18 & 81.8 & - & - & 4 & 18.2 & 22 & 100.0 \\
\hline & Total & 246 & 82.3 & 25 & 8.4 & 28 & 9.4 & 299 & 100.0 \\
\hline
\end{tabular}

Table 7: Frequencies of diagnostic and non-diagnostic fractures and undamaged microliths in the samples from Geometric Kebaran Neve David and Natufian el-Wad Terrace.

Table 8 presents the occurrences of single and multiple fractures for each of the archaeological samples. Trapeze/rectangles and medial parts of backed microliths from Neve David exhibit a variety of fracture types, the most common being single parallel fractures initiating on a retouched edge removing only a tip (type a2, Fig. $11: 3,4)$ and fractures along a sharp edge (type b1), among them deep, prominent fractures with a clear oblique orientation, similar to fractures observed on experimental lateral blades (Fig. 11: 5, 6). Multiple parallel fractures were observed only on one trapeze/rectangle. Single fractures initiating on a sharp edge across the microlith body (type b3) were observed on two medial parts of backed microliths (Fig. 11:8). This type of fracture occurred in our experiments on microliths hafted in 
a variety of modes, mostly on barbs. One medial fragment exhibited parallel and oblique/perpendicular fractures at opposite ends (type cm, Fig. 11:7).

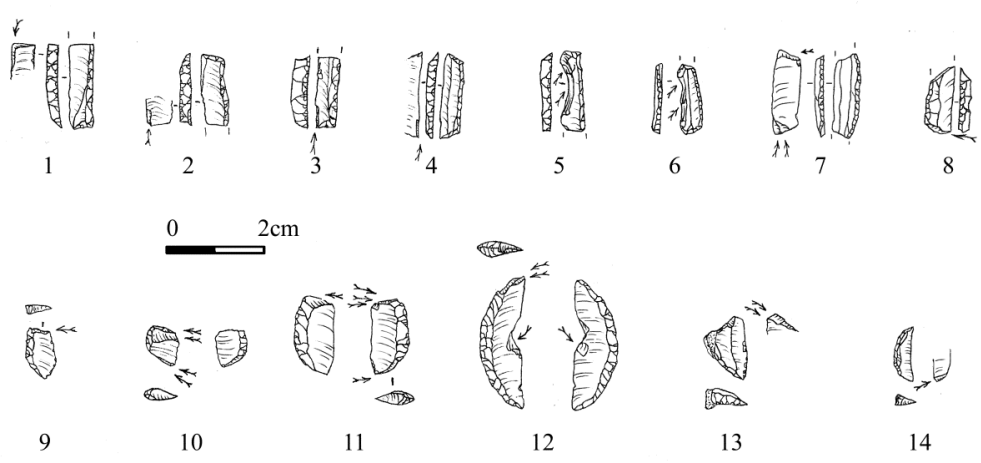

\begin{tabular}{|c|c|c|c|c|c|c|c|c|c|c|c|}
\hline \multirow[t]{2}{*}{ Site } & \multirow{2}{*}{ Type of microlith } & \multicolumn{5}{|c|}{ Single fractures } & \multicolumn{5}{|c|}{ Multiple fractures } \\
\hline & & a1 & $\mathrm{a} 2$ & b1 & $\mathrm{b} 2$ & b3 & a1m & $\mathrm{b} 1 \mathrm{~m}$ & $\mathrm{~b} 2 \mathrm{~m}$ & $\mathrm{~cm}$ & $\mathrm{~d} 2 \mathrm{~m}$ \\
\hline \multirow{3}{*}{$\begin{array}{l}\text { Neve } \\
\text { David }\end{array}$} & Trapeze/rectangle $\mathrm{N}=16$ & 2 & 7 & 5 & 1 & - & 1 & - & - & - & - \\
\hline & Medial parts $\mathrm{N}=6$ & 2 & - & 1 & - & 2 & - & - & - & 1 & - \\
\hline & Total Neve David N=22 & 4 & 7 & 6 & 1 & 2 & 1 & - & - & 1 & - \\
\hline \multirow{3}{*}{$\begin{array}{l}\text { el-Wad } \\
\text { Terrace }\end{array}$} & Helwan lunate $\mathrm{N}=14$ & 1 & - & 1 & 3 & 3 & - & 2 & 2 & - & 2 \\
\hline & Abrupt lunate $\mathrm{N}=11$ & 1 & - & 1 & 3 & 4 & - & - & 1 & - & 1 \\
\hline & $\begin{array}{l}\text { Total el-Wad Terrace } \\
\mathrm{N}=25\end{array}$ & 2 & - & 2 & 6 & 7 & - & 2 & 3 & - & 3 \\
\hline
\end{tabular}

Table 8: Distribution of single and multiple fracture types in the samples from Geometric Kebaran Neve David and Natufian el-Wad Terrace.

In the sample from el-Wad Terrace 23 of 25 lunates possessing damage diagnostic of projectile impact exhibit oblique/perpendicular fractures initiating on a sharp edge (type b) oriented either perpendicularly or in sharp angle relative to the longitudinal axis of the microlith (Fig. 11:9-14). Such fractures occurred on experimental oblique points, transversal points and barbs. Four lunates with Helwan retouch and one lunate with abrupt retouch show multiple oblique/perpendicular fractures characteristic of transversal hafting (type b2m, Fig. 11:10, 11, 12). The two exceptions with parallel fractures showed single fracture initiating on a surface (type a1), which is most characteristic for straight point, but occur on oblique points as well.

\subsubsection{Micro-fractures diagnostic of projectile impact.}

Linear striations were observed on one of the three trapeze/rectangles and on one of the seven lunates observed through SEM. In the case of the trapeze/rectangle (Fig. 12a) the striations were oriented parallel to the longitudinal axis of the microlith (Fig. 12a,b) whereas on the lunate the striations were oriented perpendicular to the longitudinal axis of the microlith (Fig. 13a,b). 

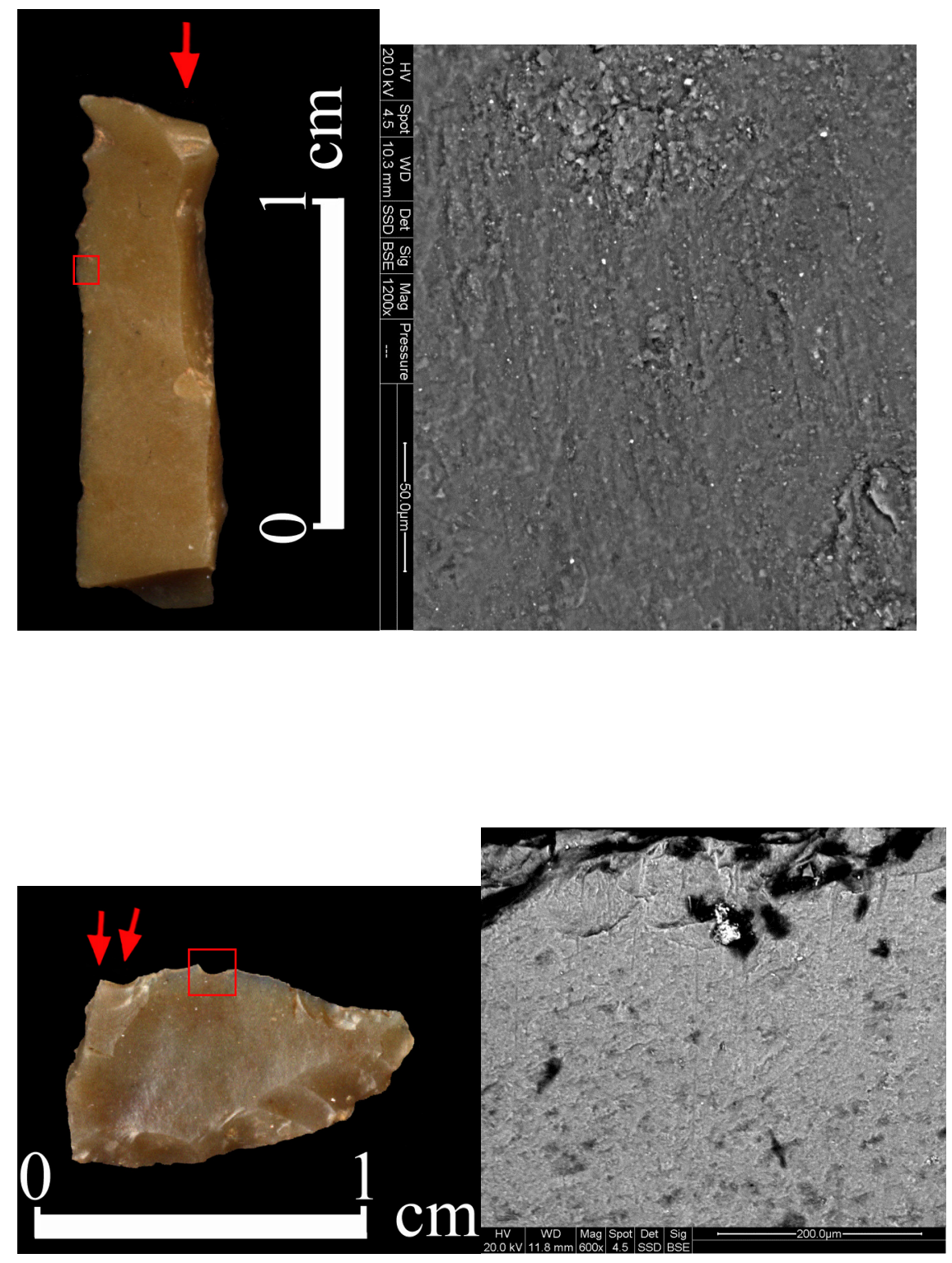

\section{Discussion}

\subsection{Experimental data}

4.1.1. Performance characteristics

The analysis of efficiency of differently designed arrows showed a correlation between arrow design and performance characteristics. The self-pointed arrows with lateral blades appeared to be efficient in all the tested characteristics whereas the arrows with tips composed of one or two microliths demonstrated contrasting attributes. Transversal points are the most efficient in terms of 
penetrating depth and durability, but have a relatively high frequency of ricochets; oblique points show good penetration values and low frequency of ricochets, but appear to be less durable. Double oblique points are durable, but have a high frequency of ricochets and relatively low penetrating abilities. This may be explained by the blunt angle formed by the lunates in our experimental arrows. At the same time, while their penetrating ability is relatively less than other designs it is still sufficient to cause a fatal wound, particularly if poison was applied (Clark, 1977).

The variability in performance characteristics between differently designed arrows can be explained in terms of the morphological characteristics of the arrowheads' cutting edges. In order to produce a deep wound the arrowhead must penetrate the hide as well as cut an opening which would be wide enough to allow the shaft to enter with negligible friction (Friis-Hunsen, 1990). Thus, the plan view angle of the frontal tip and the width of the projectile head are the most important parameters influencing wound depth. A sharper frontal angle and greater arrowhead width increase arrow efficiency in terms of penetration depth. Hafting a microlith as a straight point fixes the width of the projectile head equal to the width of the microlith. As a result the opening produced by the arrowhead is relatively small which increases friction and does not allow deep penetration, notwithstanding the relatively sharp angle of the leading tip. Oblique hafting increases the width of a projectile head while still keeping the angle of the frontal tip sharp, a combination which explains the high values of penetration depth for arrows with obliquely inserted microliths. Transversal hafting of a microlith at the tip produces a projectile head width equal to the microlith's length, which is the maximal width possible with use of a single microlith. This accounts for the greater values for penetration depth even though the design does not involve a pointed tip. Self pointed arrows with numerous lateral blades combine all the characteristics of efficient cutting projectiles as attachment of lateral blades along both sides of the shaft increases the width of the projectile head and the long sharp edges formed by the lateral blades reduce friction thus enhancing penetrating abilities (Friis-Hunsen, 1990). The relatively greater weight of such projectiles comprises an additional characteristic that increases the depth of the wound (see Cundy, 1989 and Dietrich, 1996 for analysis of the influence of projectile weight on penetrating abilities). The efficiency of arrows with numerous lateral blades has been demonstrated experimentally by a large sample of arrows fitted with elements hafted into slots parallel to the shaft or in a slightly oblique angle, as well as attached directly to the shaft with adhesive alone (Nuzhnyy, 1999). The low values of penetrating abilities shown by double oblique points, a design providing considerable width of the projectile head, can be explained by the wide angle of their frontal tip (Friis-Hunsen, 1990; Odell and Cowan, 1986). The high frequency of ricochets among double oblique points compared with the low frequency of ricochets among straight and oblique points supports this hypothesis.

The differences in the durability indices can be explained by differences in the location of the microlith on the shaft and by the extent of protrusion of the microlith from the adhesive. Hafting as straight points leaves a considerable part of the microlith exposed upon impact whereas hafting as double oblique and transversal 
points allows embedding most of the microlith's surface into the adhesive leaving only the sharp edge exposed. The durability of self-pointed arrows with lateral blades can be explained by the location of the microlithic elements along the shaft which is less vulnerable at impact. However, self-pointed projectiles with multiple lateral blades have an obvious disadvantage, specifically the relatively greater investment of time and labor required for their preparation which involves shaping the pointed shaft, preparing and attaching several microliths that must be fitted in terms of size, as well as cutting grooves when needed. The retooling of such projectiles would involve resharpening the point, as well as replacement of missing blades. In addition, these arrows are heavier and more cumbersome to use. In contrast, arrows with one or two microliths set as tips are easier to prepare as the microlithic points can be hafted with minimal or no preparation of the distal part of the shaft, they are light and convenient to use and retooling is relatively simple.

\subsubsection{Projectile damage patterns in the context of microlith hafting mode}

- The experiments have demonstrated that most types of single fractures diagnostic of projectile impact can occur on differently hafted microliths and cannot provide a reliable base for reconstructing mode of hafting.

- The most reliable data for reconstructing hafting modes are multiple fractures of the same type that appear either on the same end (proximal or distal) or on opposite ends of the microlith. Straight points are particularly associated with multiple fractures at opposite ends, oriented one towards the other as well as with multiple fractures on the same end that appear on the dorsal and ventral surfaces. A similar type of fracture, "bifacial spin-off fractures", on straight points was described in the experimental study of Fischer et al., (1984).

- Transversal points are especially characterized by multiple fractures initiating on the sharp edge of the microlith either on the same end or on opposite ends and oriented in a sharp or straight angle relative to the longitudinal axis.

- Oblique hafting can be identified by multiple fractures that initiate on the sharp edge of the microlith and remove its tip in a blunt angle or by the combination of parallel and oblique/perpendicular fractures on opposite ends of the microlith.

- A single parallel fracture initiating on a retouched edge and crossing the microlith body is also characteristic mostly of straight points (see also Nuzhnyy, 1990, 1993), although this type of damage may occasionally occur on long non-geometric microliths hafted as barbs as a result of removing the arrow from the target.

- Lateral blades can be identified by deep, pronounced fractures with oblique orientation that remove a considerable part of the sharp edge of the microlith.

- The direction of micro-fractures is not always perfectly consistent with the hafting mode of the microlith. In our experiments striations 
oriented parallel to the longitudinal axis of the microlith occurred, as expected, on straight points and on lateral blades. However, obliquely oriented fractures on transversally hafted microliths and striations directed roughly parallel to the longitudinal axis on obliquely hafted microliths indicate movement of the microlith during impact.

4.1.3. Frequency of projectile fractures

The frequency of projectile damage is influenced by a number of factors.

- The mode of hafting and the design of the arrow: single straight and transversal points resulted in the highest frequency of projectile damage whereas the lowest frequency was observed among lateral blades. Single straight points show higher values than arrows composed of straight points with additional barbs. This difference is connected to the frequent retirement of these arrows due to damage of the barbs.

- The microlith morphology: lunates, especially those with Helwan retouch, were damaged less frequently when hafted as barbs compared with other types of microliths. Moreover, lunates were damaged to a lesser degree (or less severely) when hafted as transversal points when compared with trapeze/rectangles hafted in the same mode. This is notwithstanding similarity in terms of types of fractures observed on different types of microliths in accordance with the mode of hafting.

\subsubsection{Taphonomy of projectile microlithic elements}

Our taphonomic analysis of microlithic implements has shown that more then $40 \%$ of shot microliths are expected to be lost in hunting activity. The rest can be returned to the habitation site either inside the game or in the arrows. Based on the frequency of damage diagnostic of projectile impact among the microliths recovered from the target and from the arrows, and taking into consideration that in a real hunting situation damaged microliths embedded in the arrows could have been replaced, we suggest that projectile damage expected to be found in archaeological assemblages range between 7.9-26.5\%. The lower value represents the frequency of diagnostic damage among microliths recovered from the goat carcass while the larger value is the frequency of microliths with projectile damage recovered from the carcass and from the arrows combined. It should be remembered, however, that this range was calculated based on all the microliths used, without taking into account the mode of microlith hafting which was shown to affect the frequency of projectile damage. Four experimental microliths recovered from the target without any damage at all indicate that part of archaeological undamaged microliths did participate in hunting activity.

In sum, our experiments have shown that arrow design affects its efficiency, as well as damage patterns in accordance with microlith morphology. Thus, the attempts to reconstruct the design of archaeological projectiles fitted with microliths must take into consideration a variety of data, particularly types and frequencies of 
projectile damage, morphology of microliths and performance characteristics of the arrows.

\subsection{Interpretation of archaeological material}

The samples analyzed in the study revealed differences in terms of the frequency of projectile damage in general, as well as in terms of the distribution of projectile fracture types. In the sample of trapezes/rectangles parallel fractures and fractures along a sharp edge dominate. The presence of prominent and deep fractures along a sharp edge and insignificant occurrence of fractures indicating hafting as straight points in conjunction with the low frequency of projectile damage suggest that the trapeze/rectangles were hafted predominantly as side elements, most probably as lateral blades attached parallel or in a slight angle to the shaft (Fig. 14: 13). Hafting parallel to the shaft is supported by longitudinally oriented microfractures observed on the trapeze/rectangle from Neve David.

The sample of Natufian lunates is characterized by an absolute dominance of oblique/perpendicular fractures including multiple fractures on one or both ends which is diagnostic of transversal hafting at the tip of the projectile. The direction of micro-fractures observed on one of the Helwan lunates also indicates transversal hafting. The two exceptional lunates exhibiting parallel fractures suggest that alongside hafting as transversal points other hafting modes were employed. The frequency of projectile damage in the sample of lunates is considerably higher than among the trapezes/rectangles, but still is relatively low, close to the minimal value indicated by the taphonomic analysis. The relatively low frequency of projectile fractures in the sample of lunates may also provide indirect evidence for variability of hafting modes (Fig. 14: 4-6) since in the experiments transversal hafting resulted in high frequencies of projectile damage. The frequency of projectile fractures among the lunates from el-Wad Terrace is comparable to frequency observed on lunates from the Late Natufian site Eynan (Ein Mallaha) where projectile fractures were observed on 12 of 60 investigated lunates (Marder at al., 2007). The use as transversal tips alongside additional hafting modes was also indicated by use-wear analysis on lunates from other Natufian sites (Anderson-Gerfaud 1983; Richter, 2007).

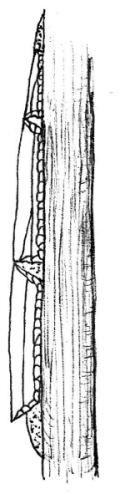

1

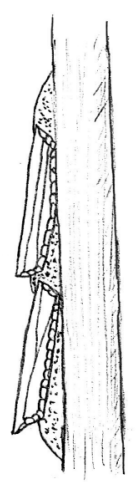

2

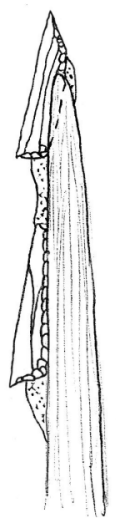

3

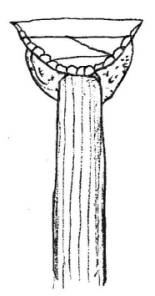

4
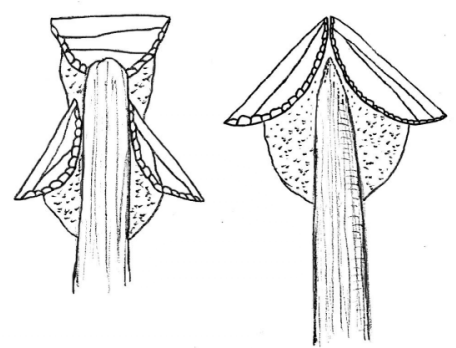

5 
The indicated shift from hafting trapeze/rectangles mostly as lateral elements of the projectiles to transversal and/or oblique hafting of lunates as projectile tips correlates with changes in knapping techniques and blank selection for microlith production characteristic for the two cultures. Projectiles composed of numerous elements hafted along the shaft require standardized width and thickness and flat lateral profile of the microlithic inserts. Geometric Kebaran trapeze/rectangles are characterized by their standardized width and thickness achieved through the selection of appropriate thin blanks and extensive retouch. Accordingly, the Geometric Kebaran knapping technique is highly homogeneous and oriented toward uniform bladelet production, which fills the need for a large series of standardized blanks (Yaroshevich, 2006). In contrast, hafting of a single microlith at the tip of the projectile does not require the production of numerous standardized components. This is in accordance with the "flexible" flint knapping technology and production of lunates on a variety of blanks, characteristic of the Natufian (Belfer-Cohen and Goring-Morris, 2002; Delage, 2005). The shift in the morphology of the dominant microlith from trapeze/rectangles to lunates may be explained by the durability of lunates when hafted transversally and obliquely when compared with other types of microliths hafted in the same mode as indicated by the experiments.

Temporal changes in microlithic variability linked to transformations in projectile design have been indicated for the Upper Paleolithic and Mesolithic in Europe. Extensive experimentally based research of the Late Pleistocene - Early Holocene microlithic assemblages in the Ukraine revealed a shift from the hafting of elongated backed microliths predominantly as side inserts to a variety of hafting modes for smaller geometric microliths, mostly on the tip of the projectile, including hafting as transversal points (Nuzhnyy, 1990, 1993). This shift in projectile design, generally similar to the dynamics revealed in the present study, was explained in terms of technological developments towards more efficient production of projectile heads. Archery experiments and analysis of a sample of microliths from an Early Mesolithic site in Belgium have shown that the Pre-Boreal to Boreal increase in the number of non-geometric microliths and reduced frequency and morphological diversity of geometric microliths reflect a shift to hafting microliths mostly as tips of the projectiles together with a reduction in the use of barbs (Crombe et al., 2001). Another example of projectile transformation associated with temporal change in microlithic variability was indicated based on an analysis of flint assemblages from the Boreal and the Atlantic sites in the Kamenice River Canyon of the Czech Republic. Here production of microlithic backed bladelets and triangles, hafted as straight points and probably as barbs, was replaced by blade-based production of trapezes hafted as transversal points (Svoboda et al., 2007).

In the Levant the transformation in projectile design is associated with the transition to sedentary settlements-a change which implies intensified use of resources within an area of several hours walking distance from the base site. The introduction of lighter, easily prepared and efficient projectiles associated with the 
evidence of a broadened diet can be explained by a need to efficiently exploit previously unused resources in a restricted area. The introduction of transversal arrowheads may indicate a hunting strategy based on tracking down animals as this kind of point forms a wound large enough to create a blood trail (Clark, 1959). Another consequence of reduced mobility which might directly affect projectile weapon technology is a change in the attitude to the ownership of territory in conditions of growing population density. The recovery of the Helwan lunate from the vertebra of a human skeleton provides evidence for inter-group conflicts during the Natufian (Bocquentin and Bar-Yosef, 2004).

Projectile weapons were in use in the Levant starting at least from the early Upper Paleolithic (Bergman, and Newcomer, 1983; Shea, 2006). While no direct evidence of preserved weapons from the Late Pleistocene in the region were found (Valla, 1987), experiments with both weapon types have shown that spear and arrowheads receive similar types of fractures diagnostic of projectile impact (Fischer et al., 1984; Odell and Cowan, 1986; Cattelain, 1997).

It has been indicated, however, that the use of flint points as tips of spears resulted in more prominent fractures in terms of their size and frequency than their use as arrowheads (Fischer et al., 1984). The size of the fractures on our experimental transversal points is similar to those observed on the lunates from elWad Terrace which indicates that Natufian hunters used bow. The use of the bow and arrow also fits the evidence for the broadening of the diet range during the Natufian as this type of weapon allows for extended trips required in a restricted area and can be used in the hunting of a wide variety of game (Yu, 2006).

\section{Conclusions}

Archery experiments with differently designed arrows fitted with various types of microliths representing Epipaleolithic cultures of the Levant allowed us to analyze the performance abilities of the arrows, to follow patterns in the occurrence of types and frequencies of projectile fractures according to the mode of microlith hafting and type of microlith, to define damage indicative of particular hafting modes and to estimate the frequency of projectile damage expected to be found in archaeological samples. The data obtained through our experiments, in conjunction with the analysis of microliths from archaeological assemblages, provide an explanation for the temporal change in microlithic variability during the Middle-Late Epipaleolithic in terms of transformations in the design of projectile weapons. We suggest that the shift in the type of the dominant microlith from trapeze/rectangle to lunate was associated with a different approach to the design of projectiles, namely, a decrease in the use of microliths as lateral components of the projectiles and their predominant hafting as tips, including transversal points.

The change in projectile design associated with the emergence of the Natufian culture probably reflects a demand for flexible, light and efficient projectiles requiring low time and labor investment for preparation and retooling. Through use of a variety of designs, each of which has its own advantages in terms of performance, the Natufians could exploit the available resources in a more efficient way and thus sustain their large communities, as well as to protect their 
territory. The use of such efficient weapons by sedentary populations may have played an important role in the Late Pleistocene - Early Holocene shifts in subsistence strategies.

Our study was based on experiments intended to represent a wide range of projectile designs and types of microliths. As a result, the samples of arrows with a particular design fitted with a particular type of microlith were relatively small which precludes detailed statistical analyses. Certain phenomena indicated in the present study require further experimental investigation, for example the durability of lunates hafted as transversal and oblique points and barbs compared with trapeze/rectangles. Performance characteristics of small lunates defining the Final Natufian as well as of wide trapeze/rectangles typical for the desert facies of the Geometric Kebaran also have to be examined. A more comprehensive analysis of fracture types resulting from projectile impact on microliths hafted as lateral blades is also required.

The suggested shift in projectile design associated with the emergence of the Natufian has to be confirmed through investigation of additional samples from Geometric Kebaran and Early Natufian sites. Investigation of microlithic assemblages representing the whole sequence of Epipaleolithic cultures, including the different phases of the Natufian will provide a more comprehensive picture of dynamics in projectile weapon design during the period when these tools proliferated in the Levant.

\section{Acknowledgments}

The experiments were financially supported by the Irene Levi Sala CARE Archaeological foundation. We would like to thank D. Hadash, N. Levin, O. Zackhaim and G. Halun for their help in arranging the experiments and Dr. Alex Berner and Larissa Popilevsky from the Electron Microscopy Centre at the Faculty of Materials Engineering, Technion for the SEM analysis. Special thanks are given to Lior Weissbrod for his comments on an earlier version of the article. We also thank John Shea, George Odell and an anonymous reviewer for their constructive comments.

\section{References}

Anderson-Gerfaud, P. C., 1983. A consideration of the uses of certain backed and lustered stone tools from Mesolithic and Natufian levels of Abu-Hureyra and Mureybet (Syria). In: Cauvin, M.-C. (Ed.) Traces d'utilisation. Sur les outils Neolithiques du procje orient. Maison de l'Orient: Lyon, pp. 77-105. 
Bar-Oz, G. 2004. Epipaleolithic Subsistence Strategies in the Levant: A Zooarchaeological Perspective. American School of Prehistoric Research Monograph Series. Boston: Brill Academic Publishers, Inc.

Bar-Yosef O., 1970. The Epi-Palaeolithic Cultures of Palestine. Unpublished Ph.D. Thesis, Hebrew University, Jerusalem.

Bar-Yosef O., 1995. Prehistoric Chronological Framework. In: Levy, T.E. (Ed.) The Archaeology of Society in the Holy Land. London: Leicester University Press, pp. xiv-xvii.

Bar-Yosef, O., Valla, F., 1979. L'e'volution du Natoufien: nouvelles sugestions. Paleorient 5, 145-151.

Barton, R. N. E., Bergman, C. A., 1982. Hunters at Hengistbury: some evidence from experimental archaeology. World Archaeology 14, 236-248.

Belfer-Cohen, A., Bar-Yosef, O., 2000. Early sedentism in the Near East - a bumpy ride to village life. In: Kuijt, I. (Ed.) Life in Neolithic Farming Communities. Social Organization, Identity, and Differentiation. Kluwer Academic/Plenum Publishers, New York, pp. 19-37

Belfer-Cohen, A., Goring-Morris, N., 2002. Why microliths? Microlithisation in the Levant. In: Elston, R.G., Kuhn, S.L. (Eds.), Thinking Small: Global Perspectives on Microlithization. Archaeological Papers of the American Anthropological Association 12, pp. 57-68.

Bergman, C. A., Newcomer M. H., 1983. Flint arrowhead breakage, examples from Ksar Akil. Journal of Field Archaeology 10, 238-243.

Bocquentin, F., Bar-Yosef, O., 2004. Early Natufian remains: evidence for physical conflict from Mt. Carmel, Israel. Journal of Human Evolution 47(1), 19-23.

Brooks, R. R. R., Wakankar, V. S., 1976. Stone Age Painting in India. New Haven, Yale University Press, London.

Caspar J.-P., De Bie, M., 1996. Preparing for the hunt in the Late Palaeolithic camp at Recem, Belgium. Journal of Field Archaeology 23, 437-460.

Cattelain, P., 1997. Hunting during the Upper Paleolithic: bow, spearthrower, or both? In: Knecht, H. (Ed.), Projectile Technology. New York and London: Plenum Press, pp. 213-240. 
Cattelain, P., Perpère, M., 1994. Tir expérimental de sagaies et de fléshes emmanchees de pointes de la Gravette. Actes du colloque internationalle "Les Sites de Reconstitutions Archéoloqgiques, Archéosite d'Aubechies-Beloeil, September, 1993, 94-100".

Clark, D. J., 1959. The Prehistory of Southern Africa. Penguin, London.

Clark, J. G. D., 1969. The Mesolithic Settlement of Southern Europe. Greenwood Press, Publishers, New-York.

Clark, D. J. 1977. Interpretations of prehistoric technology from Ancient Egypt and other sources. Part 2: Prehistoric arrow forms in Africa as shown by surviving examples in traditional arrows of San Bushmen. Paleorient 3, 127-150.

Clark, D.J., Philips J. L., Staley, P. S., 1974. Interpretations of prehistoric technology from Ancient Egypt and other sources. Part 1: Ancient Egyptian bows and arrows and their relevance for African prehistory. Paleorient 2, 323-388.

Crombe, P., Perdaen, Y., Sergant, J., Caspar, J.-P., 2001. Wear analysis on Early Mesolithic microliths from the Verrebroek Site, East Flanders Belgium. Journal of Field Archaeology 28, 253-269.

Cundy, B. J., 1989. Formal Variation in Australian Spear and Spearthrow Technology. BAR Series 546. BAR, Oxford.

Delage, C., 2005. The Natufian lithic industry: interprative challanges and new insights. Mitekufat Haeven. Journal of the Israel Prehistoric Society 35, 229-243.

Diamond, J., 2002. Evolution, consequences and future of plant and animal domestication. Nature 418, 700-707.

Dietrich, D., 1996. Bowhunting Big Gaim. North American Bowhunting Association, Chicago.

Edwards, P., 2007. A 14000 year-old hunter-gatherer's toolkit. Antiquity 81, 865876.

Fischer A., Hansen, P.V., Rassmussen, P., 1984. Macro- and micro- wear traces on lithic projectile points. Experimental results and prehistoric examples. Journal of Danish Archaeology 3, 19-46.

Friis-Hunsen, J., 1990. Mesolithic cutting arrows: functional analysis of arrows used in the hunting of large game. Antiquity 64, 494-504. 
Garlake, P.S., 1987. Themes of the Prehistoric Art of Zimbabwe. World Archaeology 19(2), 178-193.

Geneste, J. M., and Plisson, H., 1990. Technologie fonctionelle des pointes a cran Solutreennes: l'apport des nouvelles donnees de la grotte de Combe Sauniere (Dordogne). In: Kozlowski, J.K. (Ed.), Les Industries a Pointes Folliacees du Paleolithiqe Superior Europeen. Liege: E. R. A. U. L., pp: 293-320.

Goring-Morris, A. N., 1995. Complex hunter/gatherers at the end of the Palaeolithic. In: Levy, T.E. (Ed.), The Archaeology of society in the Holy Land. London: Leicester University press, pp. 141-168.

Goring-Morris, A. N., Belfer-Cohen, A., 1998. The Articulation of cultural processes and late Quaternary environmental changes in Cisjordan. Paleorient 23(2), 71-93.

Gvosdover, M. D., 1952. A composite point from the Paleolithic site of Talitskij. Scientific Notes of Moscow State University158: 207-210 (in Russian.)

Hayden, B., 1979. Ho-Ho nomenclature committee. The Ho-Ho classification and nomenclature committee report. In: Hayden, B., (Ed.) Lithic Use-Wear Analysis. New-York, Academic Press, pp. 133-135.

Henry, D. O., 1989. From Foraging to Agriculture: the Levant at the End of the Ice Age. Philadelfia: University of Pennsylvania Press.

Kaufman, D., 1987. Excavations at the Geometric Kebaran site of Neve David, Israel: a Preliminary Report. Quartar 37-38, 1989-1999.

Leroi-Gourhan, A. 1983. Une tete de sadaie a armature de lamellas de silex a Pincevent (Sceine- et - Marne). Bulletin de la Société Préhistorique Francaise 80:154-156.

Liber, N., 2006. The Natufian Stratigraphy of El-Wad Terrace as Seen through a Techno-Typological Analysis of the Lunates. Unpublished MA thesis, University of Haifa (in Hebrew).

Lombard, M., Pargeter, J., 2008. Hunting with Howiesons Poort segments: pilot experimental study and the functional interpretation of archaeological tools. Journal of Archaeological Science 35, 2523-2531.

Marder, O., Pelegrin, J., Valentin, B., Valla, F., 2007. Reconstructing microlith shaping: archaeological and experimental observations on Early and Final Natufian lunates at Einan (Ein Mallaha), Israel. Eurasian Prehistory 4, 99-158. 
Moss, E., Newcomer, M. H., 1982. Reconstruction of tool use at Pincevent: microwear and experiments. In: Cahen, D., (Ed.) Tailler! Pour Quoi Faire: Prehistorie et Technologie Litique II-Recent Progress in Microwear Studies. Studia Praehistorica Belgica 2. Tervuren: Koninklijk Museum voor Midden Africa, pp. 289-312.

Munro, N., 2004. Zooarchaeological measures of hunting pressure and occupation intensity in the Natufian. Implications for agricultural origins. Current Anthropology $45, \mathrm{~S} 5-\mathrm{S} 34$.

Nuzhnyy, D. 1989. L'utilisation des microlithes geometriques et non geometriques comme armatures de projectiles. Bulletin de la Societe Prehistorique Francaise 86 (3), 88-96.

Nuzhnyy, D., 1990. Projectile damage on Upper Paleolithic microliths and the use of bow and arrow among Pleistocene hunters in the Ukraine. The Interpretative Possibilities of Microwear Studies. Proceedings of the International conference of lithic Use-Wear analysis, 15-17th February 1989 in Uppsala, Sweden. AUN 14, Uppsala, pp. 113-124.

Nuzhnyy, D., 1993. Projectile weapons and technical progress in the Stone Age. Traces et Function: les Gestes Retrouves Colloque International de Liege Editions ERAUL, vol, 50, 11-53.

Nuzhnyy, D., 1993. The preliminary results of experiments with Aurignacian split based points production, hafting and usage. Prehistoire Europeenne, 13: 117-132.

Nuzhnyy, D., 1999. Microlithic projectile weapons of the Late Palaeolithic and Mesolithic hunters of the Crimea. Archeologija, 1, 5-24. (in Ukrainian).

Odell, G.H. 1978. Préliminaires d'une analyse fonctionnelle des pointes microlithiques de Bergumermeer (Pays-Bas). Bulletin de la Société Préhistorique Francaise 75:37-49.

Odell, G. H., Cowan, F., 1986. Experiments with spears and arrows on animal targets. Journal of Field Archaeology 13, 195-212.

Peterson, M. 1951. Mikrolithen als Pfeilspitzen. Ein Fund aus dem Lille Loshult Moor Ksp. Loshult, Skane. Meddelanden frn Lunds Universitets Historiska Museum, vol 4:123-137.

Richter, T., 2007. A comparative use-wear analysis of late Epipalaeolithic (Natufian) chipped stone artefacts from the Southern Levant. Levant 39, 97-122. 
Shea, J.J., 1988. Spear points from the Middle Palaeolithic of the Levant. Journal of Field Archaeology 15, 441-450.

Shea, J.J., 2006. The origins of lithic projectile technology: evidence from Africa, the Levant, and Europe. Journal of Archaeological Science 33, 823-846.

Shimelmitz, R., Barkai, R., Gopher, A., 2004. The Geometric Kebaran microlithic assemblage of Ain Miri, Northern Israel. Paleorient 30(2), 127-140.

Stiner, M. C., Munro, N. D., Surovell, T. A., 2000. The tortoise and the hare: smallgame use, broad-spectrum revolution, and Palaeolithic demography. Current Anthropology 41, 39-73.

Svoboda, J., Hajnalová, M., Novák, M., Šajnerová, A., Yaroshevich, A., 2007. Mesolithic settlement and activities in rockshelters of the Kamenice River Canyon, Czech Republic, Eurasian Prehistory 5(1), 95-127.

Valla, F. R. 1984. Les industries de silex de Mallaha (Einan) et du Natufien dans le Levant. Memoirs et Travaux du Centre de Recherches Francais de Jerusalem No 3. Paris: Association Paleorient.

Valla, F.R., 1987. Les Natoufiens connaissaient -ils l'arc? In: Stordeur, D., (Eds.) La Main et L'outil. Manches et Emmanchements Prehistoriques. Table Ronde C.N.R.S. tenue a Lyon du 26 au 29 novembre 1984 sous la direction de D. Stordeur. G. S. Maison de l'Orient Diffusion de Boccard, pp. 165-174.

Valla, F., Khalaily, H., Valladas, H., Kaltnecker, E., Bocquentin, F., Cabellos, T., Bar-Yosef-Mayer, D., Dosseur, G., Regev, L., Chu, V., Weiner, S., Boaretto, E., Samuelian, N., Valentin, B., Delerue, S., Poupeau, G., Bridault, A., Rabinovich, R., Simmons, T., Zohar, I., Ashkenazi, S., Huertas A. D., Spiro, B., Mienis, H. K., Rosen, A. M., Porat, N., Belfer-Cohen, A., 2007. Les Fouilles de Ain Mallaha (Eynan) de 2003 a 2005: Quatrieme Rapport Preliminaire. Journal of the Israel Prehistoric Society 37, 135-383.

Weinstein-Evron, M., Kaufman, D., Bachrach, N., Bar-Oz, G.,. Bar-Yosef Mayer, D. E., Chaim, S., Druck, D., Groman-Yaroslavski, I., Hershkovitz, I., Liber, N., Rosenberg, D., Tsatskin, A., Weissbrod, L., 2007. After 70 years: new excavations at the el-Wad Terrace, Mount Carmel, Israel. Mitekufat Haeven. Journal of the Israel Prehistoric Society 37, 37-134

Yaroshevich, A., 2006. Techno-morphological aspects of microlithic projectile implements: examples from the Levantine Geometric Kebaran and the East 
European Epigravettian, Archaeology Ethnology \& Anthropology of Eurasia 28(4), $8-17$.

Yu, P-L., 2006. Implicating projectile technology in changing systems of huntergatherer mobility. In: Sellet, F., Greaves, R., Yu, P.-L., Archaeology and Ethnoarchaeology of Mobility, Gainesville: University Press of Florida, pp. 201-220.

Figure Captions

Figure 1a. Main types of Levantine Epipaleolithic microliths: arched backed bladelet, Kebara point, trapeze/rectangle, microgravette, Helwan lunate, lunate with abrupt retouch. 